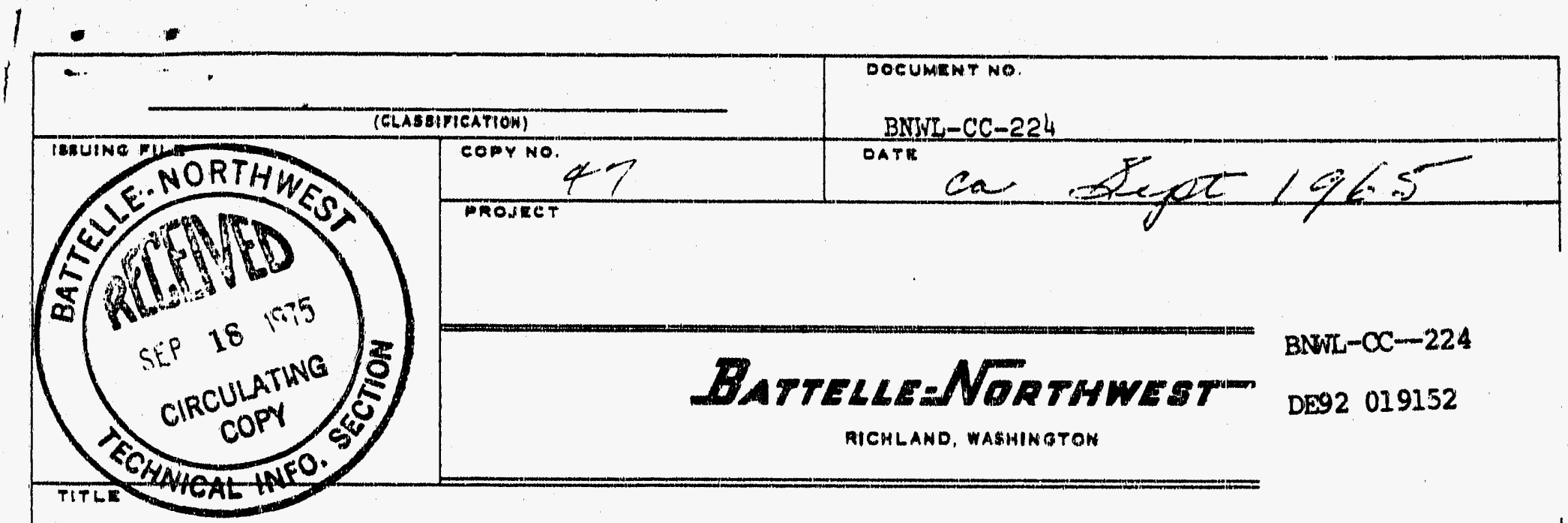

AN EVALUATION OF HANFORD WATER TREATMENT PRACTICES

AUTHOR

C. J. Tounil.1

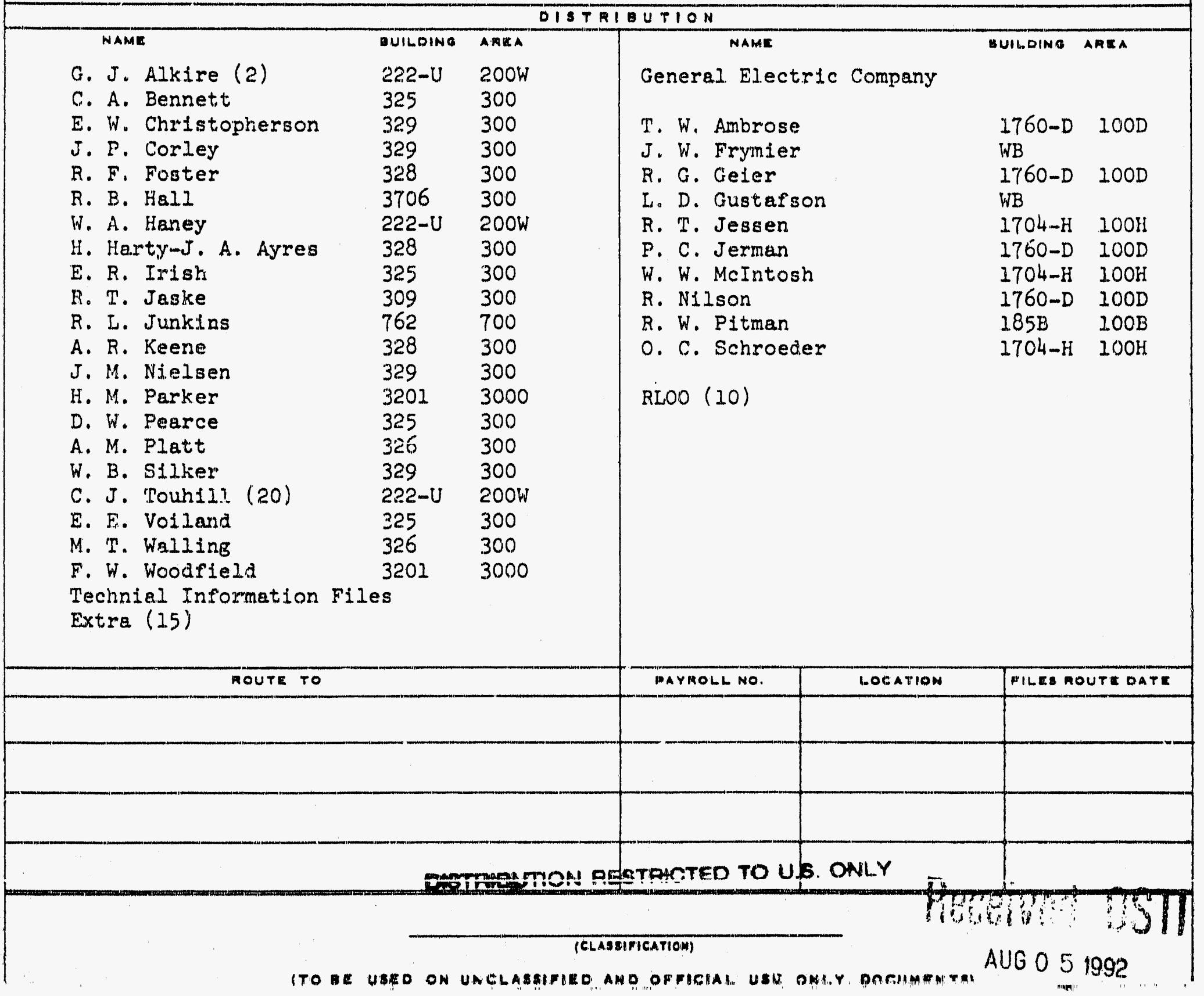




\section{AN EVALUATION OF HANFORD WATER TREATMENT PRACTICES}

by

C. J. Toun 111

Process Research and Developanent

Chemistry Department

Classified by: C. J. Touhill

\section{INFORMATION CUNCERNING USE OF THIS REPORT}

\section{PATENT STATLis}

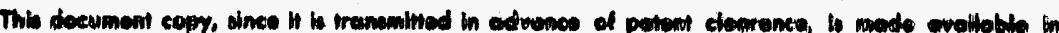

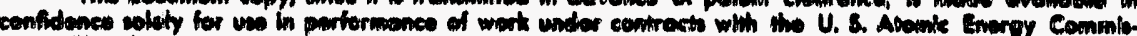

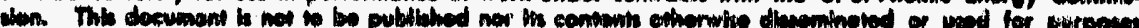

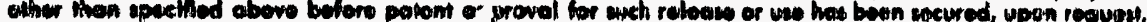

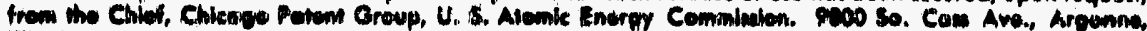
Allimats.

\section{PRERIMINAKY REHORT}

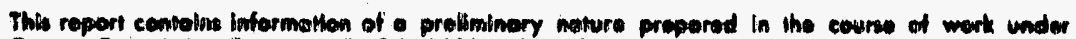

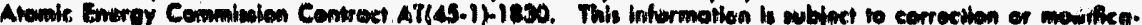

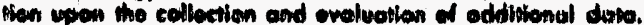

\section{LEGAL NOTICE}

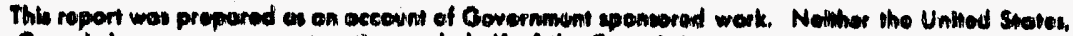

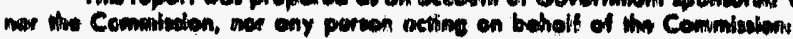

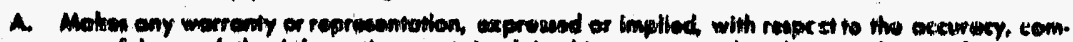

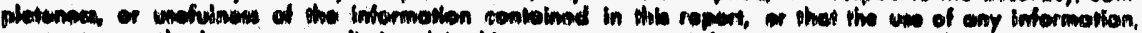

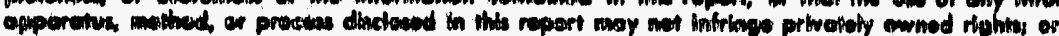

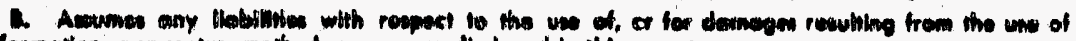

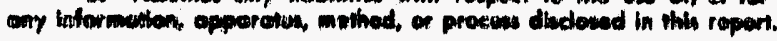

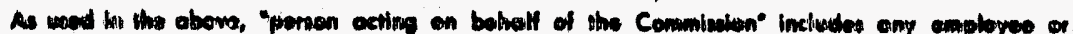

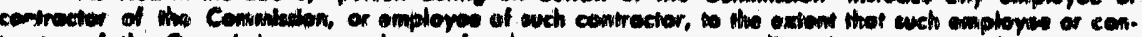

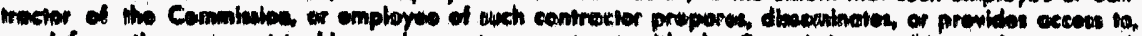

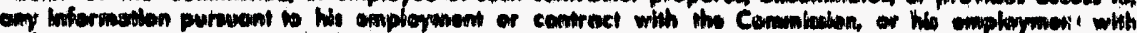
weh esominotios.

\section{PACIFIC NORTHWEST LABORATORY}

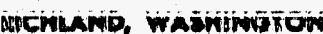

operaved by

BATTEUS MEMORIA
for tho 
BNWL-CC-224

\title{
AN EVALUATION OF HANFORD WATER TREATMENT PRACTICES
}

C. J. Touhill, Research Engineer

Process Research and Development

CHEMISTRY DEPARTMENT

BATTELLE-NORTHWEST

Richland, Washington

\begin{abstract}
:
An evaluation of Hanford reactor proless water treatment practices was made in an effort to ascertain the reasons for variations in the effluent activity between reactors. Recommendations are made for improvements in unit processes as well as for the over-all treatment process based on field inspection of the water treatment plants. In addition, a research program is proposed. to supplement the recomendations. The proposed research is designed to uncover methods of more efficient filtration as well as other procedures which might eventualiy lead to significant effluent activity reductions. The recommendations and research results will be applied toward process optimization.
\end{abstract}




\section{TABLE OF CONTENTS}

I. Introduction I

II. Process Observations and Recomendations I

A. Chemical Feed 2

1. Chlorine 2

2. Dichromate 5

3. Sulfurlc Acld 5

4. Alum 5

5. Polyelectrolyte 10

B. Mixing 13

C. Floceulation 14

D. Sedimentation 15

E. Filtration 18

F. Storage 24

G. Other Process Control Recommendations 24

III. Research Needs. 26

A. Discussion 26

B. Proposed Research 31

IV. Summary of Recommendations 32

A. Operational Recommendations 32

B. Research recomendations 34

C. Development Recommendations 34

V. Acknowledgements 35

VI. Bibliography $\quad 36$ 


\section{AN EVALUATION OF HANFORD WATER TREATMENT PRACTICES}

\section{INTRODUCTION}

From the inception of the Hanford Project there has been a continuing effort to reduce the cost of water treatment and to produce higher quallty water. Signfficant reductions have been effected by several innovations presently in use. These are:

1. Multimedia filtration beds.

2. Microphotometric turbidimetry.

3. Polyelectrolyte filter conditioning.

In 1960 , a program to reduce the amount of radioactivity in reactor effluent was initiated. Studies led to the adoption of the high coagulant feed process.

Hanford reactor process water treatment plants are perhaps the most efficient plants in existence. Every major breakthrough in water treatment has been incorporated into the plants. Thus, until some revolutionary new concept appears, plant modifications will be subject to the "law of diminishing returns."

Attention has been focused recently on the fact that effluent activities vary between plants, often quite considerably. This report evaluates Hanford water treatment practice with the aim of uncovering reasons for such variations and modes of correction. In addition, research and process control techniques are proposed which may eventually lead to further effluent activity reductions.

The evaluation required the use of some classified data and in order to make this report widely available, classified material has been incorporated into a briet companion Addendum. It is possible to make full use of the report without necessarily referring to the Addendum, although a complete understanding of recomendations is enhanced by the availability of that section.

II. PROCESS OBSERVATIONS AND RECOMMENDATIONS

Observations and recomendations for the reactor process water treatment plant unft processes are based on field inspections conducted with the most helpful cooperation and assistance of Irradiation Processing Department personnel. The recomendations are made using acceptable engineering practice and existing water treatment theory as the criterie for process modification. 
The economics of process modifications were not considered, and as a result, speafic implementation of these recommendations must be based on a benefitcost analysis.

\section{A. Chemical Feed}

\section{Chlorine}

Chlorination procedures in the reactor water treatment plants appear to be effective. These procedures, however, are rather empirical and not sufficiently flexible to cope with unusual situations that may arise. The proposed Ben Franklin Dain, for example, may ulter river conditions so that modifications of water treatment techniques will be necessary. Truly effective modifications must be based on theoretical knowledge as well as practical experience, and not on practical experience alone.

Pitman (I) states that chlorine "...is added to raw water to assist iron, manganese, and certain organic material removal, and to stop slime growth." This statement broady covers reasons for chlorine usage. If only the stoichiometric relationships are considered, one can readily see that chlorine in the concentrations used in the reactor water treatment plants cannot perform all these functions. Since much of the iron, manganese, and organic material are removed by coagulation slime growth control is the primary ain of chlorination.

This reasoning is consistent with comon practice. As Babbitt (2) points out, chlorination: (1) reduces bacterial and algae load on filters, (2) Increases filter runs, and (3) controls plankton within the filters. Experience has shown that biota in the filter will not be destroyed by a total residual chlorine dose of $0.05 \mathrm{mg} / \mathrm{I}^{(3)}$. On the other hand, a residual of $0.36 \mathrm{mg} / 1$ or more results in sloughing of the schmutzdecke." At high filtration rates ( $>4 \mathrm{gpm} / \mathrm{ft}^{2}$ ) this potentio. problem is minimized.

(1) Pitman, R. W., "Water Treatment - Theory and Practices - as Used at Hanford Atomic Products Operation," AEC Document HW-83801, (August 25, 1964), p. 2.

(2) Bobbitt, H.E. and J. J. Doland, Water Supply Engineering, 4th edition, McGraw-Hill Book Company, (New York: 1949), p. 531.

(3) Canp, T. R., Water and Its Impurities, Reinhold Publishing Corp., (New York: 1963), p. 104 .

- Schnutzdecke is the mat formed on the filter surface by accumulated floc, etc. 
The actual performance of water treatment plant chlorination was judged on the basis of chlorine demand. Data used for chlorine demand calculations are found in Table A-I in the Addendum. The chlorine demand is "...the difference between the amount of free, combined or total available residual chlorine remaining at the end of the contact period. The chlorine demand of any given water varies with the amount of chlorine applied, time of contact, pH, and temperature." ${ }^{(4)}$ Note that "...the smallest amount of residual chlorine considered to be significant is $0.1 \mathrm{mg} / 1$." This Last remark will be dealt with in detail later.'

During 1964 there was fairly good agreement between reactor water treatment plants for chlorine demand (monthly averages). Thus, in most cases the chlorine demand is satisfled although certain water treatment plants have essentially no residual. Figure 1 shows how the chlorine demand varies during an annual cycle. The curve shape is reasonable since the greatest algal populations are encountered during the warm weather.

Now, to return to the remark concerning the smallest significant residual - several water treatment plants leave a residual less than the $0.1 \mathrm{mg} / \mathrm{l}$ concentration deemed as the minimum. It is recommended that this minimum of $0.1 \mathrm{mg} / \mathrm{l}$ chlorine residual be written into the water treatment standards. This value is especially important in view of the varied contact times at the different plants. Table A-II in the Addendum compares these various contact times.

Equally important is the maximum chlorine residual. It was mentioned earlier that $0.36 \mathrm{mg} / \mathrm{l}$ of residual chlorine resulted in schmutzdecke sloughing. On the other hand, Camp (5) recommends a minimum free chlorine residual of $0.2 \mathrm{mg} / \mathrm{l}$ at least twenty minutes beyond the point of chlorine application. Cox ${ }^{(6)}$ stated that a free chlorine residual of $0.2 \mathrm{mg} / 1$ to $0.5 \mathrm{mg} / \mathrm{l}$ after twenty minutes is the most frequently recommended renge. Realize, of course, that the primary concern of

(4) Standara Methods for the Examination of Water, Sewage, and Industrial Wastes, American Public Health Association, Inc. (New York: 1955), p. 81.

(5) Camp, p. 104

(6) Cox, C. R., Water Supply Control, Bulletin No. 22, Bureau of Environmental Sanitation, New York State Department of Health, (Albany: 1952), p. 86 


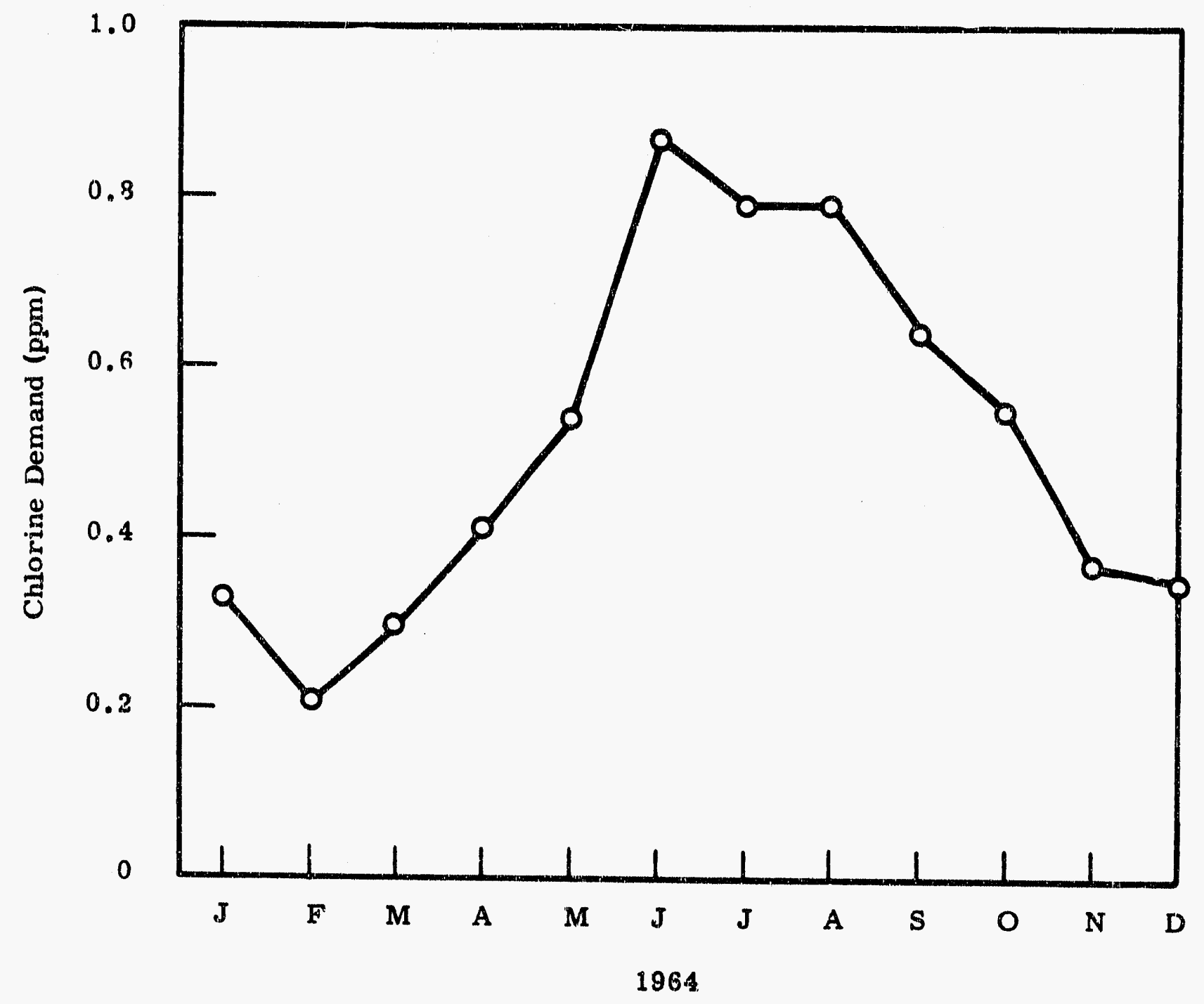

Monthly Average Chlorine Demand - 1964

PIGURE 1 
Camp and Cox is the pathogenicity of water. A free chlorine residual of $0.5 \mathrm{mg} / \mathrm{l}$ is used in the Richland, Washington, water distribution system. Hence, $0.2 \mathrm{mg} / \mathrm{l}$ chlorine residual - the maximum allowable concentration according to the water plant standards $(7)$ - appears to be a wel:-founded value, both technically and economically, and is indicative of acceptable common practice. The picture, however, is clouded by the rationale given for this maximum in the standards. The limit was imposed for corrosion control. A report by $C$. W. Kidder, $\underline{H W-T-4444}$, serves as the foundation for this apparent theoretical limit. The criterion is an outgrowth of the following statement:

"A single stage test run was made (Reference run 337, CMX Weekly Report, 8-13-44-8-19-44) at CMX (University of Chicago Metallurgy Laboratory) in which the chloride concentration was increased from the normal of $0.2-0.4 \mathrm{ppm}$ to $1.3 \mathrm{ppm}$ and $0.25 \mathrm{ppm}$ of free chlorine was present. These amounts were the maximum expected to occur in the 100 Area water systems, No effect of these additives was noticed."

It seems rather arbitrary to adhere to the limit for years purely on the basis of information which was inconclusive in the first place. Therefore, it is suggested that $0.2 \mathrm{mg} / \mathrm{l}$ chlorine residual be referred to as the recommended concentration with a $0.1 \mathrm{mE} / 1$ concentration minimum. An accompanying statement should be appended to the effect that higher concentrations may be employed should the situation require them.

Care must be exercised, however, so that the concentration of nsidual chlorine does not become too great. Cushing ${ }^{(8)}$ demonstrated that some plankton, Asterionella in particular, assimilate macro-quantities of phosphate from the river. If Asterionella were killed by chlorination, rupture of the diatom skeletal wall would release phosphate to solution. Thus, care must be exercised so that dosages great enough to kill Asterionella do not occur in water treatment plants. Fair and Geyer $(9)$ note that a free chlorine residual of 0.5 to $1.0 \mathrm{mg} / \mathrm{l}$ is sufficient to kill Asterionelle and most other common diatoms.

(7) "Process Standards - Reactor Cooling Water," AEC Document HW-27155, (Secret).

(8) Cushing, C.E. "Plankton-Water Chemistry Cycles in the Columbia River," AEC Document HW- 80500

(9) Fair, G. M. and J. C. Geyer, Water Supply and Waste Water Disposal, John Wiley and Sons, (New York: 1954), p. 817 


\section{Recommendations}

1. The maximum limit of $0.2 \mathrm{mg} / 1$ free chlorine residual should be changed to a recommended concentration of $0.2 \mathrm{mg} / \mathrm{l}$ free chlorine residual.

2. A minimum limit of $0.1 \mathrm{mg} / 1$ free chlorine residual should be: established. The added costs should be minor because ( 1 ) some plants are already operating within this limit, and (2) chlorine unit costs are relatively low.

3. High free chlorine residuals, e.g., greater than $0.5 \mathrm{mg} / \mathrm{l}$, will kill diatoms thereby, at certain times of the year, increasing the phosphate concentration in the process water. Hence, chlorine doses of this masnitude should be avolded.

4. The basis for the recommended chlorination values should be slime growth control. Corrosion control should not be cited as a basis unless experimental work shows conclusively that such is the case.

2. Dichromate

The physical addition of dichromate ions $\left(\mathrm{Cr}_{2} \mathrm{O}_{7}=\right.$ ) for corrosion inhibition conforms to acceptable engineering practice.

The zeta potential of residual alum floc or any other colloidal material which passes through the filters will be modified by dichromate addition. This modification must be considered as part of the over-a.1l water treatment scheme, especially if zeta potential control is used.

3. Sulfuric Acid

Methods used to feed sulfuric acid for $\mathrm{pH}$ adjustment conform to acceptable engineering practice. The location and amounts of acid addition, however, can be modified to improve the coagulation characteristics of alum.

Frymier $(10)$ has discussed the benefit of such modifications based on zeta potential measurements made by Silker.

4. Alum

There are numerous problems associated with alum formation by bauxite conversion in the reactor process water treatment plants". These

(10) Frymier, J W., "Preliminary Investigation of Water Coagulation Characteristics as Afrects Reactor Effluent Radionuclides," AEC Document RL-REA-922, (Secret), April, 1965.

- KE and KW water treatment plants use liquid alum feed systems. 
$-6-$

problems are both mechanical and chemical in nature. Filter alum has been produced industrialily by bauxite conversion for many years; however, it would be highly erroneous to equate alum formation at the water treatment plants with industrial alum formation. The discrepancy of process quality control is immediately apparent.

In order to consistently react a predictable amount of bauxite to form alum, several very critical ratios must be assiduously maintained. The bauxite-to-acid ratio and the water-to-acid ratio are quite critical. Imbalances in these ratios lead to substantial amounts of unreacted materials, poor stirring characteristics, and variable temperature ranges.

Several other conditions which lead to poor bauxite conversion performance are:

(1) Insufficient reagent agitation

(2) Buildup of unreacted solids in the reaction vessel

(3) Unstable steady-state maintenance

(4) Temperature deviations

(5) Metallic impurities in the feed material

When the bauxite is not mixed vigorously the reagents form a "Iumpy" slurry with a substantial amount of unreacted bauxite. This condition is aggravated when temperatures deviate from the recommended range. Further complications result from the buildup of unreacted solids, i.e., the insoluble hydrated aluminum silicates which constitute about 16 per cent of the bauxite. Such problems as these make steadystate maintenance rather difficult.

Jansen (11) performed much of the experimental work which led to use of bauxite for alum production. All of the difficulties mentioned above were noted during Jansen's experimentation. As a result of these observations, Jansen was able to establish three major interrelated criteria for alum production from bauxite. These were:

(1) The most efficient temperature range is $130 \mathrm{C}$ to $135 \mathrm{C}$

(2) Adequate agitation must be maintained in the reaction vessel at a.ll times

(3) A water-to-acid ratio of $1: 1$ must also be maintained 
Once again, these factors are interrelated and all must be maintained simultaneously.

Operation of the bauxite units does not conform to the required rigid control. The first and most obvious deficiency is temperature control. Difficulties which result from temperature variations - outside the $130 \mathrm{C}$ to $135 \mathrm{C}$ range - are: (1) detrimental changes in slurry consistency, and (2) increased amounts of unreacted bauxite. One plant has a continuous temperature recorder, some have temperature gages or the like, and a few have no reliable method whereby temperature fluctuations can be accounted for.

One procedure at the water plants was observed frequently which is minor, yet highly undesirable. The bauxite is fed from storage hoppers to the reaction vessel by a shaking tray belt-type feeder. Spillage from the tray is quite common. The operators were observed to sweep up this spillage, sometines amounting to about five minutes total feed, and place it in the reaction vessel. This, of course, briefly increases alum feed by many times. One might feel that this is a minute problem when considering the over-all process; however, it is indicative of one of the difficulties in large-scale water treatment plants.

Treatment efficiency is substantially reduced by perturbations in input process conditions. Optimum treatment is enhanced by the absence of periodicities or fluctuations; in other words, steady-state conditions produce the best quality water. The summation of occurrences such as the excess bauxite feed produces a marked deviation in process plant conditions. If zeta potential control were being practiced, the excess bauxite could possibly cause a localized concentration of unadsorbed phosphate ions or other undesirable conditions.

Alum formation from bauxite conversion complicates an already complex situation. The complexity of alum coagulation in water treatment has been recognized for many years ${ }^{(12)}$. An amalgamation of research findings, however, leads to a rairly accurate picture of what is occurring. There

(12) Babbitt, P. 442 
18 general agreenent that the optimum $\mathrm{pH}$ range for alum coagulation is erom about 5.5 to $8.3^{(13)(14)}$.

Sedlander and Gates (15) noted that, "... In the pH ramise 4 to 7.5 aluminum sol probebiy exists as equilibrian mixture of aluminum and hydrates, with mono- and divalent charges, $\left[\mathrm{AI}(\mathrm{HOH})_{5}(\mathrm{OH})\right]^{+2}$, $\left.\left[\mathrm{AI}(\mathrm{HOH})_{4} \mathrm{OH}\right)\right]^{+}$. Such forms probably polymerize with the formation of polynucleas species like $\left[\mathrm{Al}_{6}(\mathrm{OK})_{25}\right]^{+3}$. Figure 2 illustrates a mypothes 1 zed structure.

The above remarks serve to underscore the complex theory - which is not completely understood - involved when liquid alum is employed. Add to this the intricacies of" bauxite conversion, and one has a multivariable condition in a process composed of variables.

Weta potential control of water treatinent is presently being practicert at several other locations. (16) similar contro: procedures are being considored for the reactor process water treatment plants. Earlier in this section the presence of metallic impurities in kauxite was nowed. Table I shows the metallic ion concentrations. These impurities, particularly the high iron concentartion will have a distinct effect on the seta potential of colibidal alum. Inis eifecti is directiy related to the pH environment during coagulation. Bislow the isoelectric point where the alum exhluits a positive potential-determining Layer or net positive charge within the surface of shear, the iron wil tend to compact the diffuse counter-ion layer. For a net negative charee within the surface of shear (above the laselectric point) the

(13) Babbitt, p. 441

(14) Kauman, W. J., J. B. Nesbltt, M. I. Goldman, and R. Ellassen, "The Removal of Radioactive Anfoni by Water Treatiment," AEC Document NY0-151], (September, 1951), p. 93

(15) Sedlender, N. R. and C. D. Gates, "Effect of Alkyl Benzene isulfonate on Hydrous Aium Floc," Ind. Eng. Chem. Process Design and De'r. Quart. 4, 1. 55, (January, 1965)

(16) Rlddlck, 'T. M., "Zeta Potential: New Tool for Water Treatment," Chem. Ena.", June 26,1961, p. 2.1. 


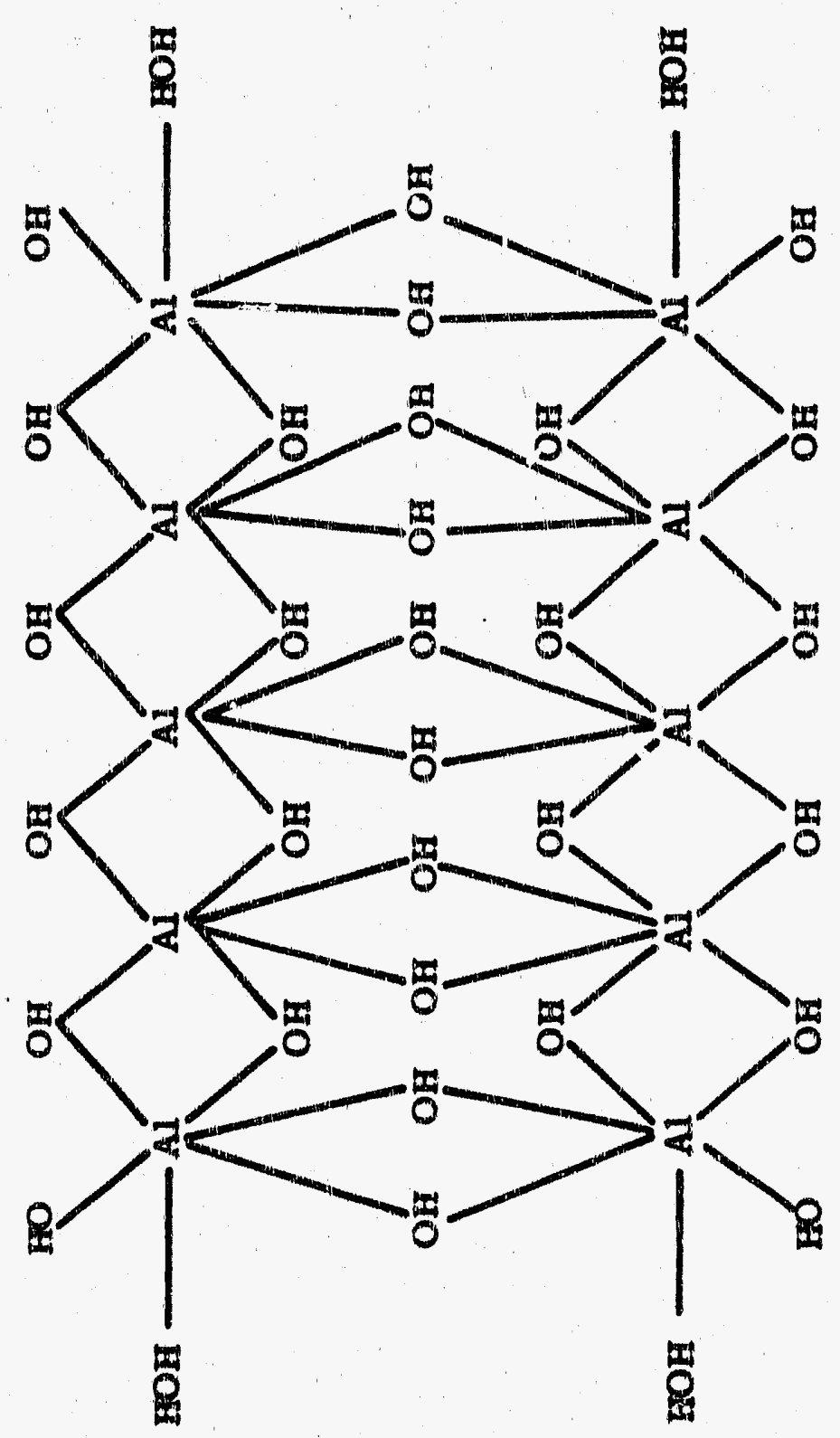

0

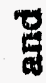

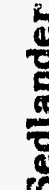

这 
Table I

Bauxite Impurities Concentration (after Jansen (11))

\begin{tabular}{cr} 
Impurity & Concentration (ppm) \\
\hline Fe & 5,000 \\
$\mathrm{TI}$ & 500 \\
$\mathrm{MB}$ & 100 \\
$\mathrm{Cr}$ & 50 \\
$\mathrm{Mn}$ & 5 \\
$\mathrm{~B}$ & 1
\end{tabular}

negative zeta potential tends to be reduced by the iron. Charge reversal may take place depending upon fonic conditions.

Kauman (17) showed experimertally that in the optimum range of coagulation, f.e., pH 5.5 to 8.3 , the mechanism of Ion removal by alum floc is principalily adsorption. Touhill and Clark ${ }^{(18)}$ have demonstrated that zeta potential and adsorption are directly related. As the zeta potential (or electrophoretic mobility") of the colloidal species incrsases, there will be a corresponding increase in the amount of adsorption of oppositely charged ions. For example, Tounil 1 and Clark showed that as the electrophoretic mobility of negatively charged colloidal manganese dioxide increases, cesium-137 (as $\mathrm{Cs}^{+}$) adsorption inereases. Migure 3 graphically shows this phenomenon.

These findings can be applied to alum as well. Thus, if the hydrogen ion concentration is adjusted so that the net charge within the surface of shear is positive, more phosphate ions (as $\mathrm{PO}_{4}{ }^{\prime}$ ) will be adsorbed as the net positive charge increases. Silker's $(19)^{4}$ data varifies this hypothesis.

\section{Recommendations}

1. Where possible, liquid alum should be used because of the degree. of control possible in adding this reagent. Also, it provides a cammon base on which all optimization trends depend.

(17) Kaufman, pg. 108

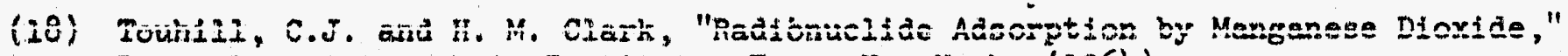
Renzselaer Polytechnic Institute, Troy, New York, (1964)

(19) Sliker, W.B., "Reducing Radioisotope Concentrations in Reactor Effluent by High Coagulant Feed," Jour. Am. Water Works Assp. 25, 3, 355, (March, 1963)

- For allute aqueous systems the electrophoretic mobility is approximately equel to 


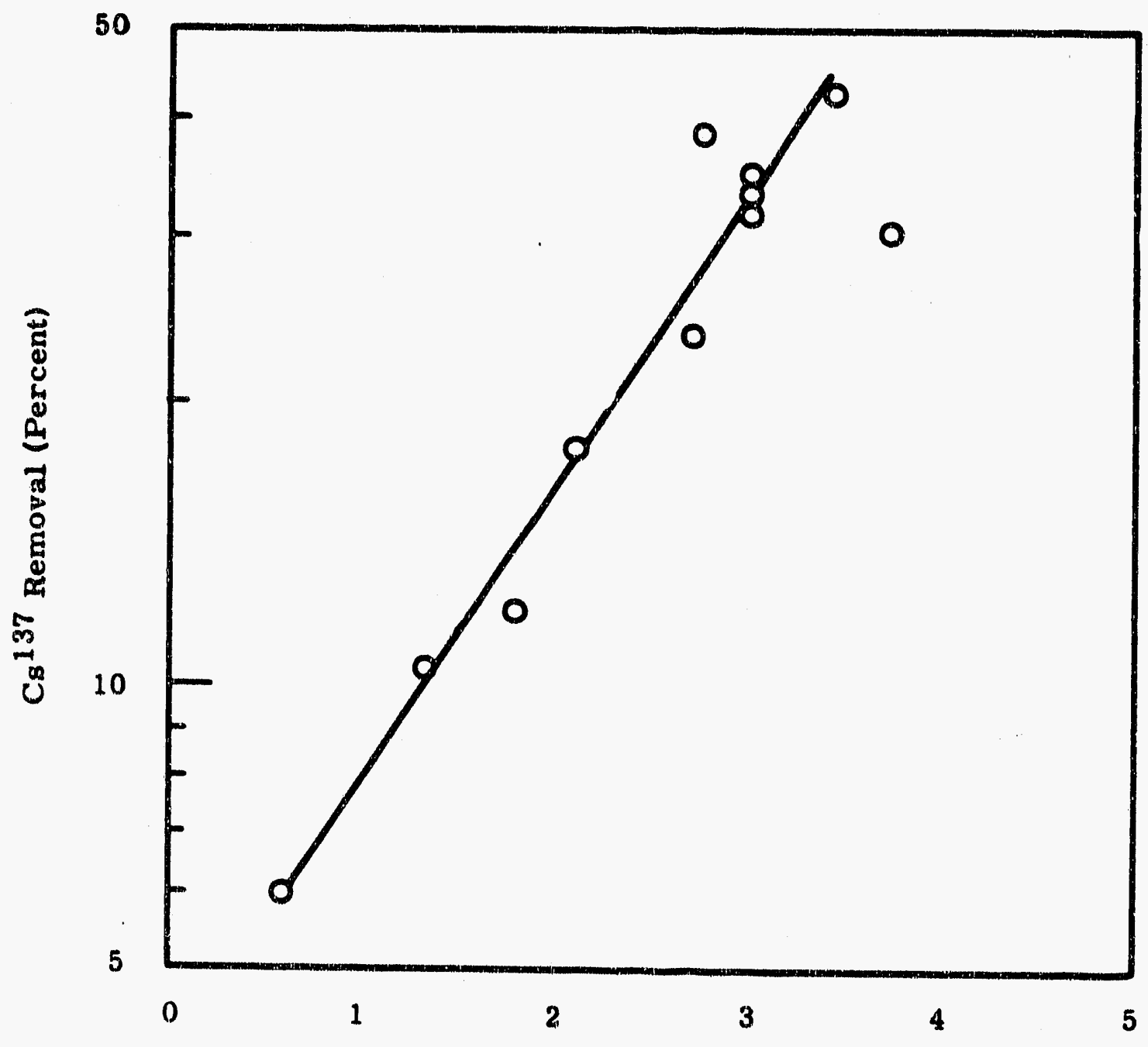

Electrophoretic Mobility $(\mu / \mathrm{sec} / \mathrm{v} / \mathrm{cm})$

Adsorption of Radiocesium by Negatively Charged Colloidal Managnese Dioxide (After Touhill and Clark) 
2. When bauxite conversion is used, a high degree of control should be maintainea, The installation of daily-inspected, continuous temperature recorders would be very useful in establishing this control. Other controls should also be employed, i.e., for the maintenance of the water-to-acid ratio.

3. Research should be performed to assess the feasibility of adjusting the head end $\mathrm{pH}$ to a value for maximum phosphate adsorption on alum (affected by an increased positive zeta potential). pH readjustment would be made after filtration for corrosion rontrol.

4. The use of zeta potential to assist process quality control is sirrongly reconmended.

\section{Polyelectrolyte}

Along with multi-media filtration, polyelectrolyte use at the reactor process water treatment plants is a significant advance in water processing technology. Water plant capacity was doubled when polyelectrolyte use was initiated, and a marked improvement in water quality was noted $(20)$. Polyelectrolytes also eliminated the need for activated silica as a coagulant aid, and provided considerable economic savings as well $(21)$.

Although polyelectrolytes are most commonly used as coagulant aids, practice at Hanford has shown that they are most effective as a filter conditioner. A review of the mechanism whereby these long chain polymers effect such a remarkable improvement in filtration characteristics would be helpful in assessing actual effectiveness of current Hanford practice.

Black (22) likens polyelectrolyte behavior to a coiled spring. In an aqueous environment the "spring" or polymer uncolis due to charges, either positive or negative, which appear at various loci on the chain. The uncoiling is due to the repulsion of like charges. The fully

(20) Pitman, p. 7

(21) Conley, W. R., C. W. Botsford, and R. W. Pitman, "Hanford Use of Experimental Water Filter Plant," AEC Document HW-45008, (August, 1956), p. 5

(22) Rlegk, A. P: "Ragic Machanisms of Coagulation:" Jour. Am. Water Works Assn.. 5'? 4, 498, (Apri1, 1960) 
expanded poi.ymer then acts as a bridge between colloldal lloc particles. Priesing (23) reels that charged locl are adsorbed preferentially on the floc by an lox exchange-type mechanisw. He also points out that so-called "non-ionic" polyelectrolytes are in fact negotively charged, and beha:e in a manner simflar to negatively charged anionic polyelectrolytes. In adition, he observes that the uncoiled length of these polymers is greater than the effective distance of the diffuse outer layer of the typical colloidal nicelle. This observation has substantial importance since it is difficult to reconcile zeta potential mesururements with discrete micellar theory. For instance, the extended polymer may include the diffuse outer layer of several micelles, yet theory l'or zeta potential measurement is based on the disurete model. Unless a phy rio-chemical interpretation, such as is found in the literature, is employed, results car be misleading.

In the case of Hanford water treatment the extention of this reasoning is apparent. Where polyelectrolytes are used as coagulant aids the zeta potential can be used to predict, as a first approximation, coagulation behavior. On the other hand, where polyelectrolytes are used as filter conditioners, filtration efficiency can be assessed by zeta potential measurements onj.y in confunction with chemical and hydraulic characteristics.

Zeta potential control cannot be relegated to only one phase such as coagulation; it must be carried through the entire treatment process for the reactor process water plants. Zeta potential control was strongly recomended in the previous section and can only be effectively applied on an integrated plant basis.

From a practical standpoint, there are several areas where polyelectrolyte utilization could be improved. Polymer dissolution, so that the chain is fully expanded, is quite critical. All treatment plants employ some type of aspiration device which alds in this dissolution. Experience by manufacturers has shown, however, that in order for the polyelectrolyte

(23) Priesing: C. P. "A Theory of Coagulation Useful for Desian," Ind. and Eng. Chem., 54, 8, 43, (August, 1962) 
feed to be fully utilized, the dry reagent should be aspirated with warm or hot water. Most Hanford plants use cold water with steam heated hot water mixing tanks. Because of the nature of the polymer, "bulking" may result if the cold water aspirator, steam-heated mixing method is used. The warm or hot water aspirator technique is superior, and involves very little additional expense. If more polyelectrolyte is dissolved using this technique, e cost sarings may be realized.

A common occurrence which is observed for most polyelectrolyte mixing tanks is tank deterioration. Mixing and feed techniques lead to highly corrosive conditions. Even frequent painting of tank surfaces does not appear to help appreciably. Corrosion products serve to reduce polymex effectiveness. Hence, experimentation should be undertaken to alleviate this problem. A possible solution might be plastic coating of tank surfaces.

Gravity flow polyelectrolyte feed devices are used in the treatment plants. Despite the fact that these devices are crude, with proper operation they appear to provide a workable feed system. It would be advisable to routinely check this feed system for constrictions and clogging. Such difficulties were observed occasionally. There seems to be a tendepcy during operation to assume that polyelectrolyte feed system is invulnerable to problems.

In some plants the polyelectrolyte is pumped to its feed point. Since the pumps used were desigmed for transmission of much larger fluid quantities, they operate highly throttled. This results in a severely agitated condition for the polyelectrolyte in the pump. Thus, the effects of severe and prolonged agitation should be investigated.

Another area which needs research is the effect of the polyelectrolyte on adsorbed ions, particularly phosphate. It was mentioned pleviously that polymers are adsorbed preferentially by the alum floc. It is possible that the meshing or bridging process displaces aldsorbed phosphate ions as well as other adsorbed ions. 


\section{Recomendations}

1. The effects of polyelectrolyte addition to alum floc immediately before flatration should be considered as part of an over-all zeta potential control program.

2. Warm or hot water, depending upon polyelectrolyte characteristics, should be used in the polyelectrolyte feed aspirator.

3. Mixing tank deterioration should be prevented.

4. The polyelectrolyte feed locations should be inspected periodically for irregular operation.

5. The effects of severe and prolonged agitation of polyelectrolytes should be investigated.

6. Research should be performed to determine the effect of polyelectrolytes on ion desorption, particularly phosphate ions.

B. Mixing

The importance of chemical mixing cannot be minimized. This fact is emphasized in the Water Treatment Plant Design Manual of the American Society of Civil Engineers (24). "The function of the initial, rapid mix is to disperse the applied chemical throughout the water to be treated. The necessity for uniform diffusion of the coagulating chemical is obvious, inasmuch as the chemical dose is proportioned to the entire flow of water into the plant, and a uniform reaction between the applied chemical and the dissolved mineral canstituents of the raw water necessitates uniform dispersion. Otherwise, some of the water would be overdosed and some would pass on without direct treatment."

Chemical mixing at the Hanford water treatment plants takes place in the influent flume. The amount of turbulence in the flume disperses and intimately mixes the reagents. Despite the fact that the mixing is apparently quite effective, mixing efficiency has never been tested. Such a test with a dye tracer could be conducted quite easily.

\section{Recommendation}

1. The chemical mixing efficiency should be evaluated using dye tracers.

(24) Water Treatment Plant Design, Amer. Soc. Civil. Engineers, Manual. of Engineering Practice No. 19, (1940), p. 26 


\section{Flocculation}

In the flocculation stage of water treatment, colloidal suspensions are caused to agglomerate by bringing the particles into contact with one another. A common index which is used to assess flocculation techniques is the temporal mean velocity gradient, $G$.

$$
G=\sqrt{C_{D} A v^{3} /(2 v V)}
$$

Where:

$C_{D}=$ coefficient of drag

$A=$ flocculator paddle area $\left(f t^{2}\right)$

$v=$ velocity of paddies relative to that of the liquid ( $\mathrm{ft} / \mathrm{sec}$ )

$v=$ kinematic viscosity $\left(r t^{2} / \mathrm{sec}\right)$

$\mathrm{V}=$ flocculator volume $\left(\mathrm{ft}^{3}\right)$

More important than this index is the product of $t$, the flocculation detention period, and $G$, which shall be referred to as the Gt factor. The Gt factor is a more important measure of flocculation effectiveness, since it accounts for the duration of flocculation as well as the mode. Fair and Geyer ${ }^{(25)}$ state that, "Experience has shown that the value of $G$ should be greater than $10 \mathrm{fps}$ per ft in order to promote flocculation but less than 75 fps per ft if disintegration of the floc by shear is to be avoided. Optimum values appear to lie between 30 and $60 \mathrm{fps}$ per ft. The detention period should be at least $10 \mathrm{~min}$. Longer times ( $30 \mathrm{~min}$ or more) are indicated for low values of $G$, and there is reason to believe that for satisfactory performance the dimensionless product of $G$ and $t$ may range within the limits of $10^{4}$ to $10^{5}$."

Both factors were calculated for the water treatment plants with extreme retention times. B water treatment plant had the shortest flocculator retention time, while $C$ water treatment plant had the longest. Temperature variations of $5 \mathrm{C}$ to $20 \mathrm{C}$ were assumed. The $\mathrm{C}$ water treatment plant, for the temperature range specified, had $G$ values considered as being consistent with good practice. The $G$ values for the $B$ water treatment plant were only slightly high. These values are indicative, especially in the case of the $C$ plant, of acceptable engineering design. 
The other important index, the Gt factor, reflects the short retention times due to the substantial increases over design flow rates. For the temperature range specified, the Gt factor, even for C plant with its longer retention time, was outside the limits of satisfactory performance.

The flocculators, therefore, perform reasonably well as far as floc promotion is concerned, but the flocculation times are highly inadequate. Only a physical expansion of the flocculation basins would correct this situation.

Although the flocculators promote very little agglomeration, they should be operated when needed to prevent accunulation of settleable material in the basins. Table A-III in the Addendum shows the probability of deposition in the flocculation basins.

\section{Recommendation}

1. Flocculators should be operated when needed to prevent settleable material accumulation in the basins.

\section{Sedimentation}

As with the flocculation basins, the sedimentation basins were designed for much lower flow rates. The higher flow rates markedly affect settling characteristics of floc particles, and decrease the probability of their deposition.

In order to assess sedimentation effectiveness, particulate removal efficiency must be known. This efficiency can be represented by the following relation:

$$
\frac{y}{y_{0}}=\frac{v_{s}}{q / A}
$$

Where: $y / y_{0}=$ proportion of particles removed in a horizontal flow basin

$$
v_{s}=\text { settling velocity }
$$$$
Q / A=\text { overflow velocity }
$$

Calculations were made for all reactor water treatment plants using the following assumptions:

1. The average floc size is $1.0 \mathrm{~mm}$ (This value is widely used by others, and has been obsorved at Hanford by Silker ${ }^{(26)}$ ) 
2. The average floc specific gravity is 1.002 (27).

3. The annual river temperature range is $5 \mathrm{C}$ to $20 \mathrm{C}$.

The following equation (Stokes' Law) was used to calculate ${ }^{\mathbf{s}} \mathbf{s}$, the settling velocity, for laminar flow conditions:

$$
v_{s}=\frac{g}{18}(s s-1) \frac{d^{2}}{v}
$$

Where:

$$
\begin{aligned}
B & =\text { gravity constant }\left(\mathrm{cm} / \mathrm{sec}^{2}\right) \\
\text { Ss } & =\text { specific gravity of the floc particle } \\
d & =\text { particle diameter }(\mathrm{cm}) \\
v & =\text { kinematic viscosity }\left(\mathrm{cm}^{2} / \mathrm{sec}\right)
\end{aligned}
$$

For nonlaminar flow conditions, Fair and Geyer ${ }^{(28)}$ have outlined a procedure for calculating $v_{s}$ for transitional flow conditions. The settling velocities at $5 \mathrm{C}$ and $20 \mathrm{C}$ were computed by these methods, and are found in Table II.

\section{Table II}

Variation of Settling Velocities with Temperature

\begin{tabular}{ccc} 
Temperature & \multicolumn{3}{c}{ Settling Velocity } & $\left(v_{s}\right)$ \\
5 C & $\frac{(\mathrm{cm} / \mathrm{sec})}{(\mathrm{gal} / \mathrm{min})}$ & 1.07 \\
$20 \mathrm{C}$ & 0.098 & 1.46
\end{tabular}

The overflow velocities (Q/A) for the various reactor areas as well as the proportion of particles removed in a horizontal flow basin (y/yo) are shown in Table A-IV in the Addendum. From the results it may be corituded that the bulk of the floc is not removed by settling. This is true even after ideal settling conditions and flow characteristics have been assumed. Plant tests have shown that short-circuiting exists in the water treatment plants. This serves to aggravate the situation to an even greater extent. It would be reasonable to assume that in some areas up to 99 per cent (possibly even more) of the floc passes over the effluent weir to the filter beds.

Some data, for instance that taken at the B water treatment plant, show that possibly this is not an intolerable situation. Maybe it is desirable 
since the floc removal on the filter beds may be enhanced by high floc loadings in some cases. At this point, however, such statements are purely speculative. Fundamental research is required to confirm or disprove this hypothesis. A later section proposes a program to include this area in an exhaustive study of filtration.

If the study, however, shows that plant operation improves with better sedimentation, methods must be devised to modify existing settling facilities. The two obvious ways to improve settling are: (1) enlarge the sedimentation basins, and (2) reduce the flow rates. Both of these solutions are completely untenable due to greatly increased costs.

There are, however, two possible modifications which are reasonable. A system of baffles and trays could be added to the sedimentation basin as shown in Figure 4. The addition of trays lengthens the effective removal path of the particle. Thus, more floc particles will be removed. Similar arrangements have been used effectively in practice.

A second possible modification employs irradiation to improve sedimentation characteristics of the floc. Research in this area has been conducted for a number of years. Recent work by Grune ${ }^{(29)}$ has shown the feasibility of improving hydrous oxide settling by irradiation. There is no doubt that floc settling is improved by irradiation - this fact has been verified by many investigations. At the present time, however, there is a dearth of practical information as to the effectiveness on a large scale. It is planned to incorporate irradiation experiments on alum floc particles applied to filter beds in the filtration research proposal in a later section.

If preliminary irradiation-settling tests prove to be effective, then it would be highly desirable to conduct pilot-type tests at a water treatment facility such as the PRTR water treatment plant or at the KE experimental water plant.

\section{Recommendations}

1. Determine during experimentation whether high floc loadings on filter beds are desirable.

(29) Grune, W. N., "Investigation of the Effects of High Energy Ionizing Radiation on Colloidal Systems and Susvensions," Preprint American Chemical Society 


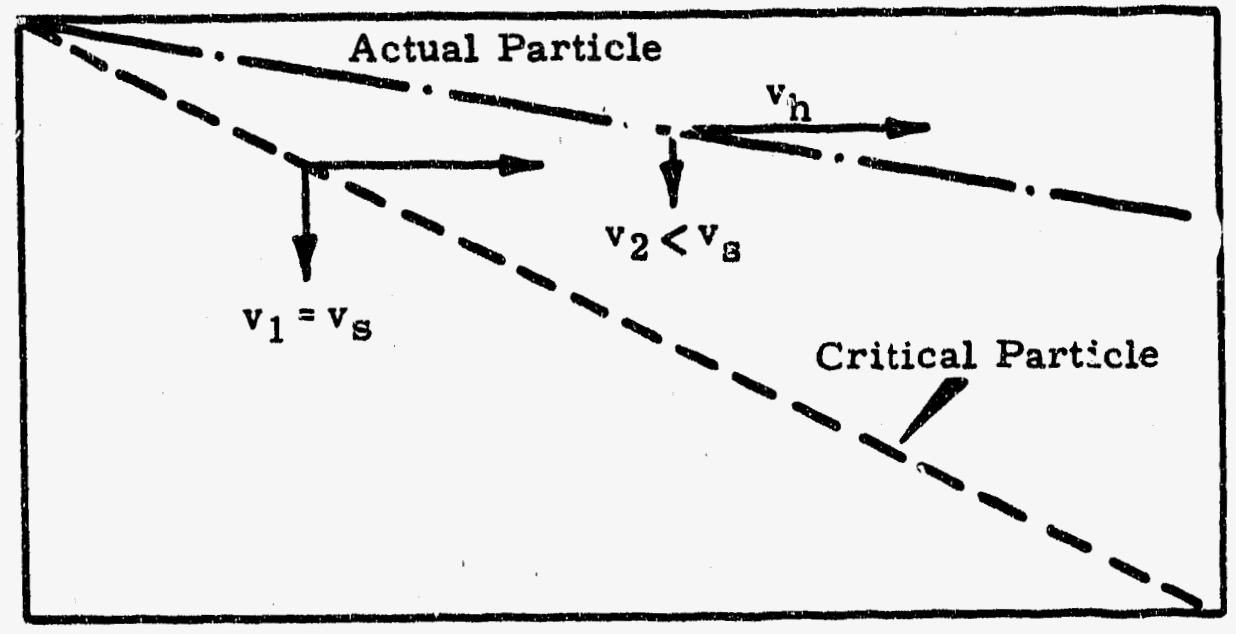

a) Unmodified Settling

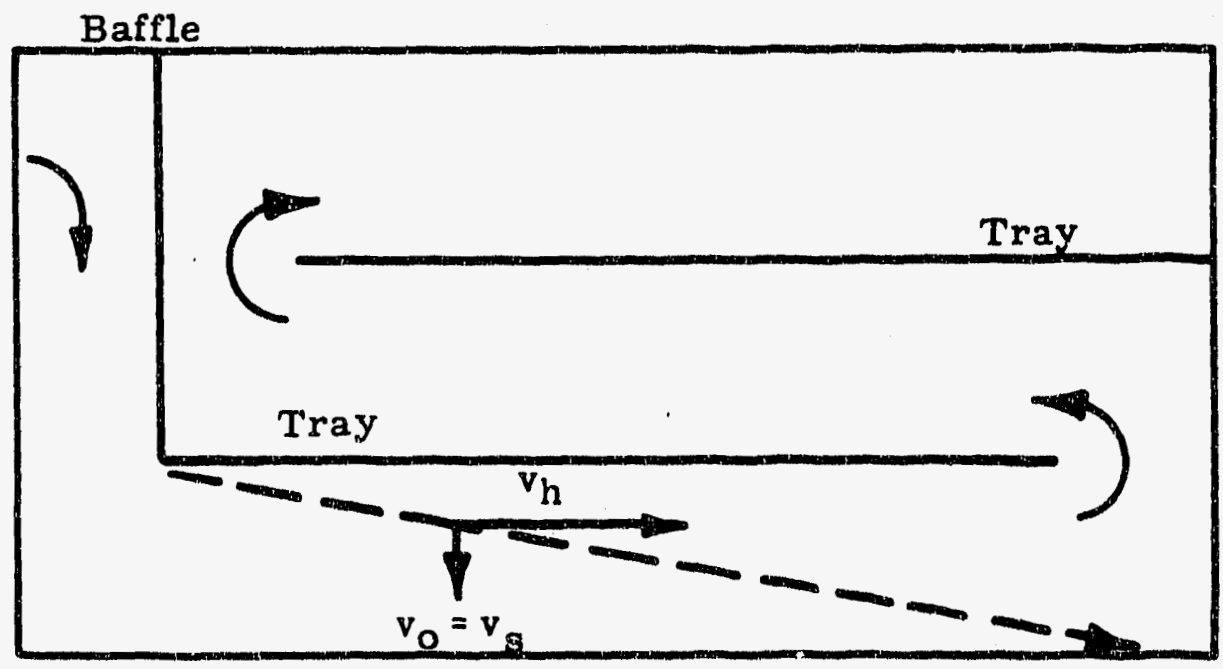

b) Modified Settling

Baffle-Tray Modification of the Sedimentation Basins

FIGURE 4 
2. If high floc loadings are not desirable, then modify existing facilities by :

a. Baffle-tray system, or

b. Irradiation - settling techniques, (dependent upon research results)

E. Filtration

This section deals with the practical aspects of filtration and some of the problems encountered during normal plant operation. The research needs and theoretical aspects will be dealt with in a later section.

Both Baylis $(30)$ and Camp $(31)$, leading experts in water filtration for many years, have acknowledged the work of Conley and Pitman at Hanford as a major advance in water treatment. Prior to the time their results were applied at the Hanford water treatment plants, normal flow rates in most filter beds were about $2 \mathrm{gpm} / \mathrm{ft}^{2}$. Present filter flow rates are several times this rate. Table A-V in the Addendum shows these present filter flow rates at the various reactor areas.

Filtration rates of the magnitude in Table A-V had been regarded as unusual, even undesirable in normal water treatment practice, and led to high head losses very rapidly. Polyelectrolytes, used for filter conditioning, minimized the head loss problem. Thus, the use of multi-media filter beds and polyelectrolytes at Hanford water treatment plants substantially increased the flow rates possible during filtration.

Many of the practical filtration problems encountered are associated with backwashing. Table A-VI in the Addendum shows the backwash rates at the reactor water treatment plants. The recommended backwash rate is $15 \mathrm{gpm} / \mathrm{ft}^{2}$. Backwash rates listed in Table A-VI are typical of low turbidity periods; however, these rates change during the year, but not appreciably.

In order to consider the effects of backwashing in more detail, the physical composition of the filter beds must be defined. Figure $5 a$ shows the newer $27 / 3$ type of filter bed which is presently used at B, D, F, KE, and KW reactor areas. Figure $5 \mathrm{~b}$ shows an older type presently used at the $C$ and H water treatment plants".

(30) Baylis, J.R., "Test Program for Filter Evaluation at Hanford - Discussion," Jour. Am. Water Works Assn., 52, 2, 214, (February, 1960)

(31) Camp, T. R., "Experience with Anthracite-Sand filters - Discussion," Jour. Am.

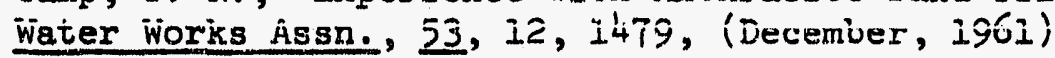

* The inactive DR water treatment slant is a newer $27 / 3$ type. Reactors $H$ and $F$ will 


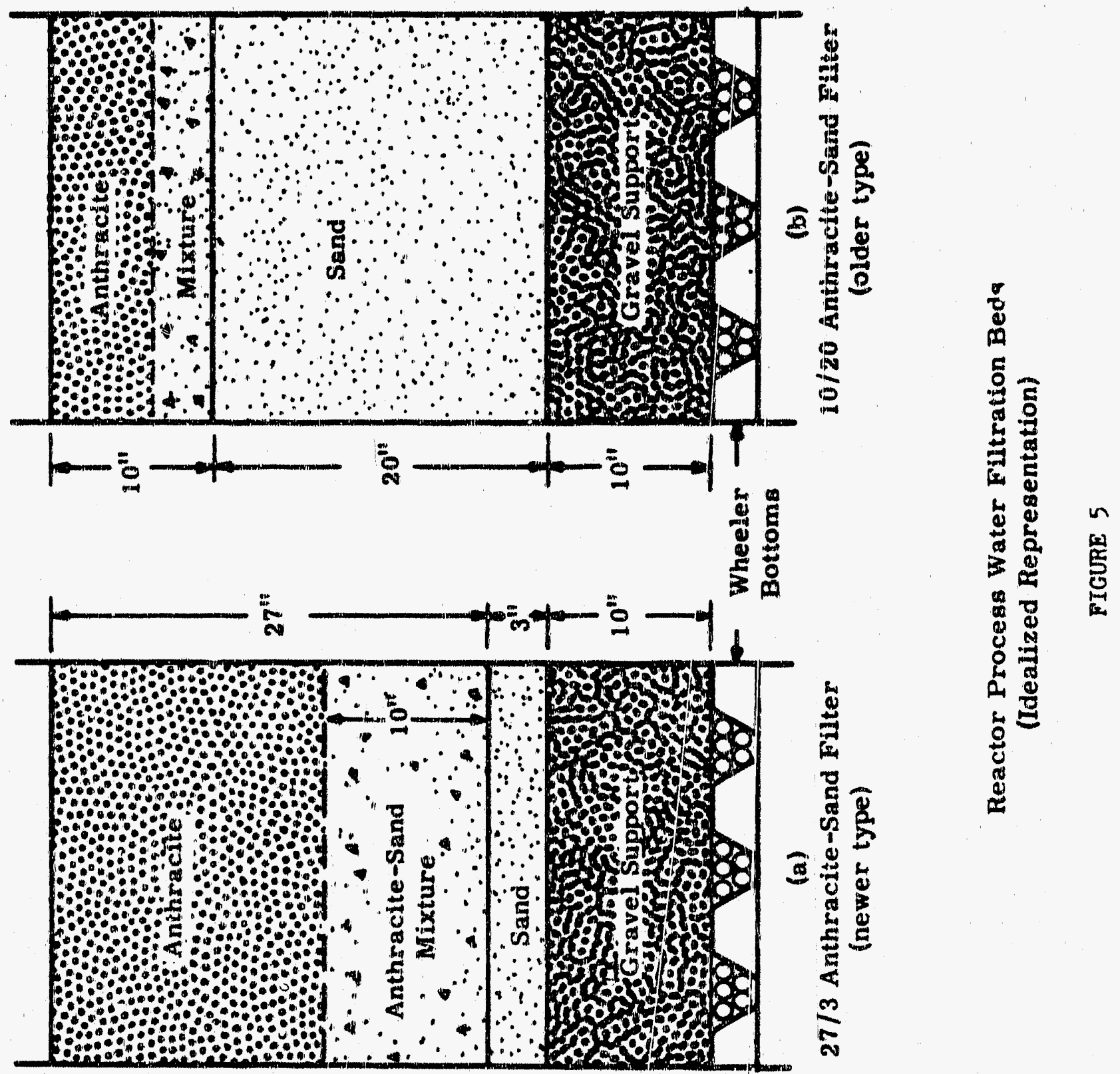


From the standpoint of river effluent activity the newer type filter beds consistently perform better then the older type. Without elaborating on the mechanism for this phenomenon, from a purely empirical view, the filters should be converted to the newer $27 / 3$ configuration.

In 1957 , the $D$ water treatment plant filter beds were converted to the $27 / 3$ or newer type. The change took place over an extended period of time, and very few records were kept regarding the changes that were made. The small amount of information which is avaliable indicates that the filter beds range from 26 inches of anthracite and 4 inches of sand to 20 inches of anthracite and 10 inches of sand. The $B, D R$, and $F$ woter treatment plants were also converted at approximately the same time. Again, very few records are available as to what changes were effected, but it seems reasonable to assune variations in these filters too.

Since filtration is the controlling unit process of Hanford water treatment, filter bed variations could easily magnify differences in operating techniques for the rest of the plant. It would be suitable, therefore, to make a statistical sampling of all beds of one type to determine: (1) if the bed compositions deviate from the $27 / 3$ configuration, and (2) the degree of deviation which exists. A statistical sampling program would provide a basis for any decision to modify or readjust the filter bed configuration.

Despite the range of values that exist for backwash rates, there does not appear to be any significant correlation between river effluent activity and filter backwash rates. There is, however, an indication that the plants with higher backwash rates produce better quality reactor effluent for the new type filter beds. One aim of the proposed filtration research is to test this hypothesis.

Proper backwashing technique requires gentle opening and closing of the backwash valves. Only in this manner can the proper stratification of filter media be maintained. Rapid opening and closing of the valves causes channeling, sand and anthracite losses, and inefficient use of the filter depth.

"he need for.scheduled backwashing is recognized; however, it seems that tile criterion of head loss is overshadowed in the process. Backwashing 
normally takes place when the head loss is seven to ten feet. As the head losi approaches ten feet a greater particulate loss through the filter bed occurs. In order to bolance the benefit of low head losses (and the associated particulate retention) and lons filter runs, a head loss or eight peet is recommended as a maximum. The backwash schedule should be adjusted accordingly.

It must be recognized that the primary reason for backwashing is to "scrub" the filter media so that enmeshed floc and particulate material (turbidity) can be discarded to waste, thereby leaving a clean filter bed. The backwash rate is especially critical in providing the most effective "scrubbing" or cleaning of the filter bed. At low backwash rates the media is not lifted or expanded sufficiently to provide complete floc and particulate removal, and at high backwash rates the media is expanded so much that there is little intra-media contact which is so important to proper cleaning. Also at high backwash rates anthracite losses become significant. Thus, some intermediate rate must be chosen which eliminates the problems of the extremes.

Just as the previous paragraph implies, media expansion is the basis for selection of backwash rates. In order to maintain a given media expansion, it is necessary to increase the backwash rate during the summer and decrease the rate during the vinter. This, of course, is due to the changes in water viscosity. Cox ${ }^{(32)}$ describes a very simple device for measuring the bed expansion. The information gained by using such a device would be extremely useful in determining reasonable backwash rates. The use of this device is recommended.

Common practice at most conventional water treatment plants bases optimum sand expansion on 40 per cent of the bed depth. At Hanford this would be an expansion of 12 inches. Pitman (33) has observed that for a beckwash rate of $15 \mathrm{gpm} / \mathrm{ft}^{2}$ the expansion is about 7 inches. Since the 40 per cent value is for a single media bed, aditional information is required regardine the expansion of a multi-media bed. This will be included in the piltration research proposal also.

(32) $\cos =\mathrm{D} \cdot 68$

(33) Pitman, MN-83801, p. 5 
Operating personnel have noticed that bed expansion appears to be markediy affected by polyelectrolyte adition. When the filter conditioner is added, bed expansion seems to be reduced compared to expansion without polyelectrolytes. These observations will be investigated in the proposed filtration research.

In the past it had been acceptable procedure to waste from 3 to 13 minutes of the filtered water immediately succeeding backwash. This procedure has largely been abandoned because it was shown that much of the initially wasted water was from the backwash. Admittedly, though, some particulate material will pass into the clear wells without the wasting. For conventional plants wasting of the filtered water is not necessary, however, for reactor process water the particulate material which does pass through may be quite deleterious.

Laboratory experiments, which are presently being conducted at BattelleNorthwest, will define the particulate size which passes through the media during normal filtration. Techniques developed could be used to determine the quantities and sizes of particulates passing to the clearwell immediately after backwashing. Pitman $(34)$ has noted that there is a definite period of filter recovery at the Hanford watex plants, and that this recovery is usually effected within 15 minutes.

Leaky backwash valves are extremely troublesome, and are encountered quite frequently. Since the e is a limit to the mechanical remedies for this undesirable situation, only a program of frequent surveillance can minimize the problem.

"Mud balls" - agglomerated turbidity, floc, and sand - are formed when the washing of filters is inadequate. Surface washing of the filter bed is quite effective in eliminating this potential problem. Surface agitation also serves to break up the heavy collofdal mat in the filter upper portion which in turn leaas to a much more effective turbidity and floc removal to waste.

Some Hanford water treatment plants do not use the surface agitation systems. In view of the demonstrated benefits which accrue from using surface agitators, thelr use is strongly recommended at all plants. 
The operators of manually backwashed filters may benefit from the use of waterproof lights in the filter, so the clarity of backwash water can be judged more easily.

During reactor outages, the water treatment plants are dormant. In the very cold weather of December, 1964, small amounts of water were allowed to flow through a plant during an outage period. The filter bed was backwashed at regular intervals despite the fact that there was no head loss buildup. When the reactor went back into operation, the effluent activity was noticeably reduced. It is possible that the reduction was due, in part, to this backwashing. This procedure is recommended on a test basis. If experience shows it to be an effective procedure, it should be adopted as routine procedure.

An expensive and troublesome problem during backwashing is the loss of anthracite in the wash water. One possible solution is to reduce the backwash rate, while increasing the backwash time. This solution would be acceptable provided the lower backwash rate effectively removes the floc and turbidity from the filter bed.

Another possible solution for preventing anthracite losses is the use of screen lips on the wash water gutters. Figure 6 shows a scheme for screen use. One problem that could be encountered when screens are used is detrimental hydraulic effects. First, the screens must be of sufficient mesh size so that flow will not be appreciably impeded. Second, clogeing of the screens will lead to poor flow characteristics: therefore, this condition should be avoided by careful choice of screens.

Sand loss into the clearwells is also a problem. Although the presence of sand in the clearwell will not affect water quality, sand loss from the filter bed definitely will. This is particularly critical for the $2 \% / 3$ or newer type filter beds. The three inches of sand in this type bed is the last barrier for turbidity, floc, or colloidal materials which would otherwise pass on to the reactor. Any loss of sand, particularly if the effects are localized, might eventually lead to channeling and reduced removal

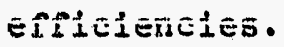


M วิด doI
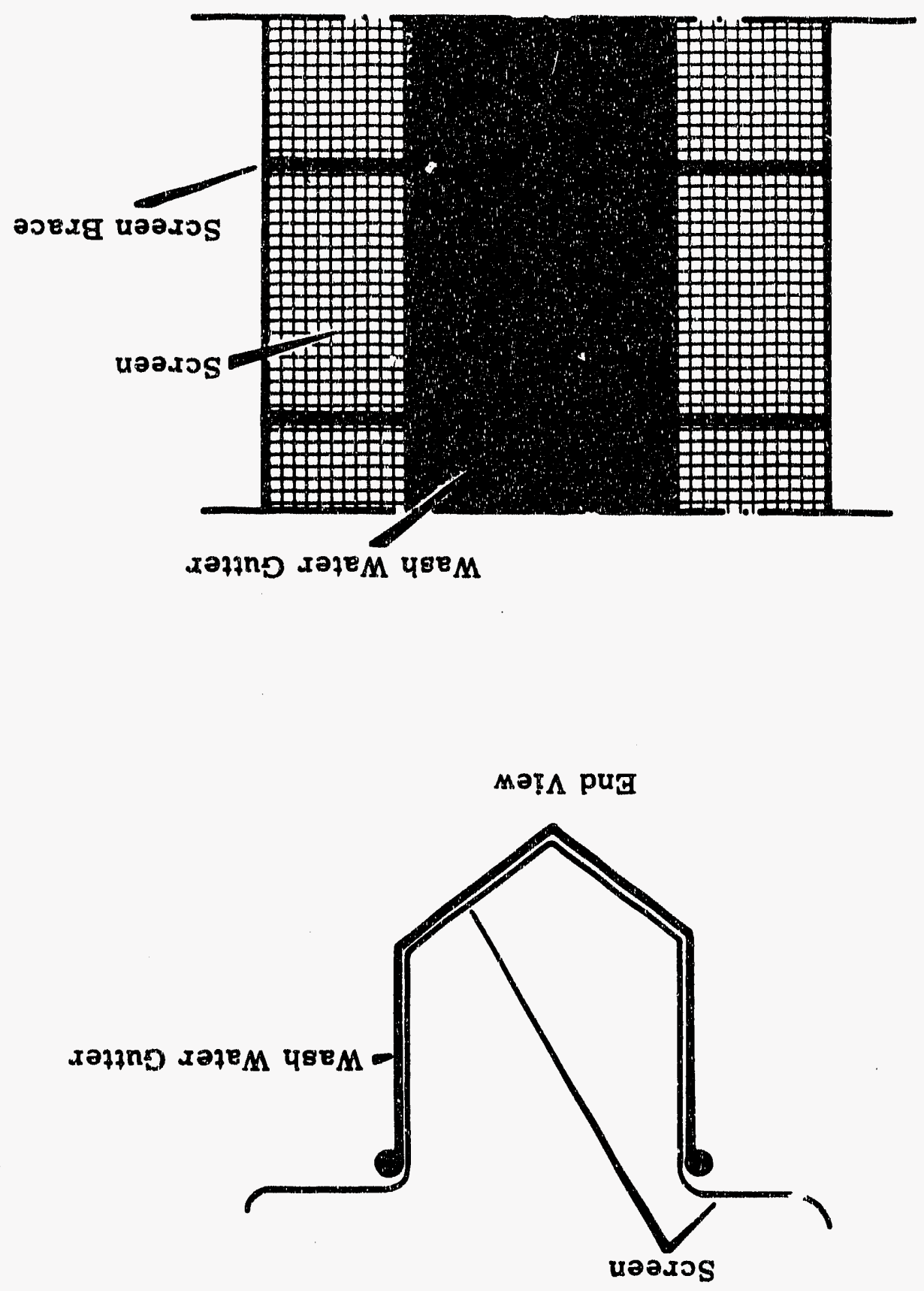
Camp $(35)$ has had practical experience with this type problem. He found that sand loss at the Billerica, Massachusetts, water treatment plant was excessive, especially when multi-media filtration and high filtration rates were instituted. As a first measure to avoid these losses the Wheeler bottoms and gravel support were reconstituted. After one year of successful operation conditions once agail. deteriorated. Porous plates were then added and have operated very successfully for several years with no sand loss. The introduction of porous plates or tile bottoms is strongly recommended at Hanford wherever possible. This measure could provide a reduction in effluent activity if used in conflunction with other recommendations made in this report. Porous plates are superior to tile bottoms, but are susceptible to plugging by the hydrous oxides of manganese and iron. At Hanford, manganese concentrations in the river are very low, and iron concentrations are low enough so that plugging would probably not be encountered. Experimentation should be undertaken to confirm this.

The practice of "bumping," used quite frequently at some water treatment plants at Hanford, is highly undesirable and should be discontinued. "Bumping" of a filter bed is caused by opening the wash-water valve for a few moments to loosen the packed material on the surface and thus prolong filter runs. During conventional water treatment this measure is only used in an emergency. For Hanford water treatment it should be used even less frequently.

\section{Recommendations}

1. All filter beds should be converted to the $27 / 3$ or newer media configuration.

2. Porous plate or tile bottoms should be used in the filter beds.

3. A head loss of eight feet is recormended as a maximum for filtration.

4. The Cox device for measuring bed expansion should be employed to assist. in establishing backwash rates.

5. Backwash rates should be based on bed expansion.

6. A bed expansion criterion of 40 per cent should be tested during the proposed research (see later section).

7. The effects of polyelectrolyte concentrations on bed expansion should also be investigated during the proposed research.

8. The practice of "bumping" of filters should be discontinued.

(35) Camp, Jour. Am. Water Works Assn., December, 1961, p. 1482. 
9. Rapid opening and closing of backwash valves is poor operational procedure and inust be avoided.

10. The surface agitators should be used during each backwashing.

11. The proposed research should test the hypothesis that higher backwash rates produce better quality water.

12. The possibility of wasting filtered water immediately after backwashing should be investigated.

13. A statistical sampling of the filter beds should be made to determine if the bed compositions deviated from the $27 / 3$ configuration, and the degree of deviation.

14. Measures should be taken to prevent anthracite losses. Possibilities are :

(a) Lower backwash rates for longer times.

(b) Anthracite screens on the wash-water gutters.

15. Backwashing at regular intervals should continue during reactor outages.

16. Any changes in the filtex beds (or any other unit process) should be well documented.

17. A regular surveillance program should be intiated to minimize the leaky backwash valve problem.

18. Waterproof lights in the filters would assist the operacors in judging the clarity of the wash-water.

\section{F. Storage}

Because of the nature of the storage facility, there is very little chance that any difficulty will be encountered in the clearwells. Some sand lost from the filter beds does accumulate in the clearwells, but the problem which this generates is the need for periodic removal.

A high percentage of lights in the viewing ports are inoperable. This is a rather minor point, but these lights often serve a useful function in the practical operational control of water treatment. Recommendation

1. A more reliable lighting system should be placed in the clearwell viewing ports, and it should be maintained on a regular basis.

G. Other Process Control Recommendations

Optimum effectiveness in water treatment is a function of the integration of all the unit processes. Hence, all preceding recommendations may not be fully effective unless they are integrated into an optimized scheme. 
Perhaps this explains why there has been only limited success in reducing effluent activity recently. Previous modifications may have been much more effective if considered for the over-al.1 process rather than on a unit process basis. It is recommended, therefore, that reactor process water treatment be optimized by means of systems analysis or linear programming techniques. Such techniques have been applied to other areas of environmental engineering with considerable success.

The aim of the optimized computer program would be to predict the optimum operating conditions for minimum effluent activity release based on measurable input conditions such as turbidity, $\mathrm{pH}$, phosphate concentration, temperature, etc. A great deal of accumulated operational data and research findings could be utilized in the formulation of the program. This recommendation, more than any other, could produce a significant reduction in effluent activity provided recomended operational techniques are assiduously adhered to. Moie effective use of existing facilities and chemical reagents could result in cost savings as well.

The formulation of an optimization program would be formidable and would require a great deal of time and effort. Since, in the past, the problem of parameter selection has stifled further work, the principal effort would be involved in selecting the parametric controls and the associated experience factors. While such a plan would be difficult, it would not be impossible. Widespread interest in similar profects has resulted in a basic technology which could be utilized at Hanford.

The Water Treatment Task Force of the Irradiation Processing Department has performed efficiently and capably since its inception. Its accomplishments indicate it may be worthwhile to establish the Task Force or a similar group permanently to assist in maintaining a high level of operational control. It would serve to centralize activities aimed toward the optimization of water treatment practices.

At the present time, the only criterion other than effluent activity for water quality control is turbidity measurement. While turbidimetry has been an effective control, other methods may provide helpful indices for 
process control. Possible methods may be zeta potential, total solids analysis (dissolved and suspended), and specific conductance.

Camp (36) points out that flow fluctuations should be avolded. This is based on evidence that erratic flow tends to result in greater amounts of suspended material passing through the filter beds. Much the same sentiments were expresised in an earlier section.

In the past, one water plant was used as a "standard." This practice is commendable and should be maintained.

\section{Recommendation}

1. A research program for optimization by computer techniques should be initiated for reactor process water treatment.

2. A permanent group such as the Water Treatment Task Force would help in maintaining a high level of operational control.

3. Other measures of water quality should be used, e.g., zeta potential, total solids, and specific conductance.

4. One treatment plant should be maintained as a standard.

\section{RESEARCH NEEDS}

\section{A. Discussion}

It is widely recognized by environmental and sanitary engineers that the limiting unit process of water treatment is filtration. Previously the limitations have usually been related to the hydraulic characteristics of the porous media, however, recent research has indicated that other factors may be equally as important. O'Melia and Crapps (37) have shown the importance of the chemical aspects of filtration. Conley $(38)$ implies that he is in agreement with this view when he states, "It is believed that filtration should be considered as an extension of coagulation, and that the two processes cannot practically be separated."

A paper by Camp (39) entitled "Theory of Water Filtration" has generated much discussion in the Journal of the Sanitary Engineering Division,

(36) Camp, T. R., "Theory of Water Filtration," Jour. Sanit. Eng. Div., ASCE, 90, SA4, 1, (August, 1964)

(37) O'Melia, C. R. and D. K. Crapps, "Some Chemical Aspects of Rapid Sand Witration," Inur: Am, Water Works Assn: $56,10,1326$; (0otoher; 1964 )

(38) Conley, W. R., "Theory of Water Filtration - Discussion," Jour. Sanit. Eng. Div., ASCE, 21, SA2, 72, (Apri1, 1965) 
Proceedings of the American Society of Civil Engineers. Most of the outstanding workers in the field have commented on it, and as a result the paper and discussion reflect the present state of knowledge of filtration mechanisms.

Camp (39) has made several observations which are quit pertinent to this report. A few of his thoughts were mentioned previously; however, some of the more important ones will be quoted below.

- "Pilot studies of backwashing are essential in the design of new filters for the selection of filter media and for measurements of wash rates and expansion required to fluidize the proposed bed." (40)

- "It is the size, concentration, and adhesive qualities of floc particles, and not their light-scattering potential, that affect the performance of a filter. Some floc particles removed by or passing through filters are colorless and transparent." (41)

- "The porosity, $p$, is the most important single filter parameter affecting head loss and length of filter run." (42)

- "For effective and economical filtration, the pretreatment should produce floc particles that are small enough to penetrate into the bed." (43)

- "Pilot plant studies...are recommended prior to the design of water treatment plants, as a means of selecting the coagulating chemicals, coagulant and filter aids, and filter media; and of determining filter rates, wash rates and size, number and dimensions of units." (44)

In commenting on Camp's paper, Ives ${ }^{(45)}$ notes that a pilot study would "... involve the time and facilities of a research institute; thus the theory must be examined carefully so that critical experiments can be planned."

(39) Camp, T. R., Theory of Water Filtxation," p. I

(40) Ibid., p. 2

(4I) Ibid

(42) Ibid., p. 6

(4j) Ioia., p. Ii

(44) Ioid., p. 28

(45) Ives, K. J., "Theory of Water Filtration - Discussion," Jour. Sinit. Eng. Div., 
Stanley (46) agrees with both Camp and Ives regarding pilot studies. He says, "For a proper analysis of the problem, it is important to evaluate the effect on capital and operating cost of such factors as coagulants, coagulant aids, filter aids, rate of flow, type of filter media, size of filter media and the proportion of the load of suspended solids to be removed by the sedimentation tanks and by the filters. The most feasible approach to the investigation of these factors is certainly through the use of small test filters."

Conley (47) had several interesting comments in his discussion of Camp's paper. He states, "...it is difficult, if not impossible, to predict whether or not filtered water quality will be satisfactory from observations on the floc entering the filter." He proceeds to state that the only way to measure the quality of the filtered water is by turbidimetry. In regard to surges Conley says that the problem, "... is minimized in the MicrofLOC bed by inclusion of extremely fine media having an effective size of from 0.15 $\mathrm{mm}$ to $0.2 \mathrm{~mm} . "$ Conley feels that pilot plant studies for a particular water are of little value due to seasonal fluctuations in water quality.

Hudson $(48)$ makes two points worth noting here while discussing Camp's paper. (1) "Taking buoyancy into account, it may be estimated that the hydraulic gradient through anthracite beds of 1.55 density during backwashing would be $0.33 . "$ (2) "The effects of surges on filters needs more observation and analysis. Available data indicate that rates of change of filtration rate greater than one per cent per minute cause impairment of water quality." $\mathrm{Deb}^{(49)}$ also agrees with Camp that pilot plant studies are necessary before many of the factors influencing filtration may be evaluated.

Eliassen (50) concurs with Camp that "...removals of floc in filters take place by the buildup of sheaths of floc particles on individual sand grains rather than by clogging of pores, or straining action..." Eliassen also

(46) Stanley, D.R., "Theory of Water Filtration - Discussion," Jour. Sanit. Eng. Div., ASCE, 21, SA2, 71, (Apri1, 1965)

(47) Conley, "Discussion," p. 73

(48) Hudson, H.E., "Discussion," April, 1965, p. 80

(49) Deb, A. K., "Discussion," p. 84

(50) Eliassen, R., "Discussion," p. 92 
points out that it is not justified to rely on turbidity measurements as a parameter of filter performance, but rather, low turbidity is the "... end result of efficient filter performance."

The final discussion of Camp's paper was written by O'Melia(51). O'Melia points out that particulate removal in sand filtration is distinguished by two separate and distinct steps: "(1) The transport of the suspended particles to the immediate vicinity of the solid-liquid interface presented by the filter (i.e., either to a sand grain or to another particle that has previously been retained in the bed), and (2) the attachment of the particles to this surface." While the particle transport is a physical process, particle attachment is essentially a colloid-chemical process. O'Melia feels that "...comprehensive theory on water filtration must include colloid-chemical factors in addition to physical-hydraulic parameters."

Regarding particulate removal, O'Melia notes that "...suspended particle cohesion to previously filtered particles will be optimum at their isoelectric pH." Factors which influence particle attachment are ionic strength of solution, double layer interactions, and van der Waals forces. o'Melia has successfully interpreted filtration phenomena using a doublelayer model. He also makes some interesting remarks about polyelectrolyte use. "(I) In many cases optimum flocculation is achieved with polymers that have the same sign as the surface electric charge on the suspended particles. (2) Optimum flocculation appears to occur when one-half of the available adsorption sites on the particles are covered. Poor flocculation results when either a smali or a large fraction of the available sites are covered. (3) A flocculated suspension can be redispersed with time even though the degree of agitation is maintained at a constant level; this redispersion is produced by the rolding back of extended polymer segments onto the particle surface, reducing the possibility of bridge formation by either mechanism." o'Melia feels that, "These observations have significant consequences when the use of high molecular weight polymers as filter aids is considered."

As mentioned previously, the paper and the discussion it generated reflect all the principal views and much of the major knowledge of filtration theory. It is important to apply this knowledge to Hanford water treatment wherever

(51) O'Melia, C. R., "Discussion," p. 92 
possible. For instance, with one exception pilot plant studies were recommended, particularly for backwashing. The objection by Conley loses validity if the pilot program is designed to reflect seasonal and annual variations in raw water quality.

On the basis of previous recommendations regarding zeta potential control, and the remarks in this section on colloid-chemical aspects of filtration, this area should be extremely fruitful in improving effluent quality.

Flow surges require research according to Hudson, and Conley has proposed a method for alleviating surge problems that may be helplul at Hanford. Research should be performed in this area also.

O'Melia mentioned some interesting facts about polyelectrolytes which should be examined along with the chemical aspects of filtration.

Turbidity measurements as the critical parameter of filtration efficiency has been called into question by several persons in the discussion. In a previous section expeximentation in this area was suggested for the following research proposal.

Camp (52) stated that floc particles must be small enough to penetrate into the filter bed. This could very well be the problem encountered at the $C$ Area water treatment plant. Inspection of the floc at this plant showed that floc size was abnormally large - much larger than any other plant inspected. The full depth of the filter bed will not be utilized due to matting of the floc in the upper layers of the filter bed. This situation could easily lead to other difficulties which are apparent in the. C Area plant.

The research needs pointed out in this section as well as in the Process Observations and Recommendations section are incorporated into a program of research planned specifically for the Hanford reactor process water treatment plants. An outline of the proposed research is found in the following section.

(52) Camp, "Theory of Water Filtration," p. 11 


\section{B. Proposed Research}

The recormendations of this report may be divided into three unit process categories: (1) improvements in the operation of unit processes, (2) improvements in the over-all treatment process, and (3) improvements in the functions and behavior of a particuler unit prosess. The proposed research deals with the third category. Since it is weli-recognized among water treatment resefurchers that the limiting unit prisess is filtration, and because the recommendations of this rieport and the work of others suggest that filtration research especially with pilot filters would be extremely productive, research on the filtration unit process is proposed.

The general scope of the proposed research is outlined below. Each of the factors has been discussed in detail elsewhere in this report.

I. Fhysical factors of fi.ltration

A. Floc loading effects

B. Polyelectrolyte effects

1. charge

2. concentration

C. How surge effects

D. Backwashing effectis

1. Backwash rate - bed expersion study

a. polyelectrolyt,e added

b. polyelestrolyte not inded

2. Expansion criteria

3. Backwash rate and time oprrelation

E. Floc sloughing and breakthrough

1. Size determination

2. Solids and turbidity coruparison

F. Underdrain systens - porouls plate plugging

II. Chemfal factors of piltration

A. Zeta potential elfects

1. Media chargeis

2. Floc charges

3. Floc-media interactions

B. Colloidal characteristics - particle attachment

C. Adsorption effects 
1. $\mathrm{pH}$ variation

2. Coagulant variation

3. Electrokinetic variation

III. Irradiation factors of Piltration

A. Settling enhancement

B. Floc modification

The research proposed in the outline will serve as a guide in an attempt to answer questions raised in this report. The research, however, should not necessarily be restricted to only the areas listed. It is possible that equally productive studies will be suggested by results gained in an earlier phase.

\section{SUMMARY OF RECOMMENDATIONS}

The recommendations of this report are collated and presented below. Three types of recommendations are presented: (1) Operational - recomendations that can be acted upon to improve the operation of the water treatment plants; (2) Research - recommendations that can be carried out only after knowledge has been gained through experimentation and research; and (3) Development - recommendations that can be carried out after verification by experimental testing.

As previously pointed out, specific implementation of these recomendations must be based on a benefit cost analysis.

\section{A. Operational Recommendations}

1. The use of zeta potential measurement to assist process quality control is strongly recoumended.

2. All filter beds should be converted to the $27 / 3$ or newer media configuration.

3. One treatment plant should be maintained as a standard.

4. When bauxite conversion is used, a high degree of control should be maintained. The installation of dally inspected, continuous tempersture recorders would be very useful in establishing this control. Other controls should also be employed, 1.e., for the maintenance of the water to acid ratio.

5. Porous plate or tile bottoms should be used in the filter berls.

6. A permanent group such as the Water Ireatment Task Force wouia heip in maintaining a high level of operational control. 
7. The maximum limit of $0.2 \mathrm{mg} / 1$ free chlorine residual should be changed to a recomended concentration of $0.2 \mathrm{mg} / \mathrm{l}$ free chlorine residual.

8. A minimum limit of $0.1 \mathrm{mg} / 1$ free chlorine residual should be established. The added costs due to this limit will be minor because (a) some plants are already operating within this limit, and (b) chlorine unit costs are relatively low.

9. High free chlorine residuals, e.g., greater than $0.5 \mathrm{mg} / 1$, will $\mathrm{kill}$ diatoms thereby, at certain tiues of the year, increasing the phosphate concentration in the process water. Hence chlorine doses of this magnitude should be avolded.

10. Where possible, liquid alum should be used because of the degree of control possible in adding this reagent. It also provides a common base on which all optimization trends depend.

11. The effects of polyelectrolyte addition to alum floc imnediately before filtration should be considered as part of an overmall zeta potential control program.

12. Warm or hot water, depending upon polyelectrolyte characteristics should be used in the polyelectrolyte feed aspirator.

13. Mixing tank deterioration should be prevented.

14. The polyeilectrolyte feed locations should be inspected periodically for irregular operation.

15. Flocculators should be operated when needed to prevent settleable material accumulation in the basins.

16. Any changes in the f1lter beds (or any other unit process) should be well documented.

17. Rapid opening and closing of backwash valves is poor operational procedure and must be avoided.

18. A regular surveillance program should be inltiated to minimize the leaky backwash valve problem.

19. The surface agitators should be used during each backwashing.

20. Waterproos lights in the filters would assist the operators in judging the clarity of the wash water. A more rellable lighting system should be placed in the clearwell viewing ports, and it should be maintained

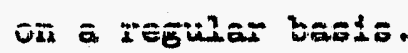

21. Backwashing at regular intervals should continue during reactor outages.

22. The practice of "bumping" of filters should be discontinued.

23. A head loss of eight feet is recomended a maximum for filtration. 


\section{B. Research Recommendations}

1. Indices of water quality, in addition to turbidity, should be used, e.g., zeta potential, total solids, and specific conductance.

2. Research should be performed to assess the feasibility of adjusting the head end $\mathrm{pH}$ to a value for maximum phosphate adsorption on alun (effected by an increased positive zeta potential). pH readjustment would be made after filtration for corrosion control.

3. The effects of severe and prolonged agitation of polyelectrolytes should be investigated.

4. Research should be performed to determine the effect of polyelectrolytes on ion desorption, particularly phosphate ions.

5. Determine during experimentation whether high floc loadings on filter beds are desirable.

6. If high floc loadings are not desirable, then modify existing facilities by: (a) Baffle - tray system, or

(b) Irradiation - settling techniques, (dependent upon research results).

7. A bed expansion criterion of 40 per cent should be tested during the proposed research.

8. The effects of polyelectrolyte concentrations on bed expansion should also be investigated during the proposed research.

9. A lang term research program should be initiated to determine the parametric controls and experience factors to be used in the optimization of reactor process water treatment by computer techniques.

\section{Development Recommendations}

1. The chemical mixing efficiency should be evaluated using dye tracers.

2. A statistical sampling of the filter beds should be made to determine if the bed compositions deviate from the $27 / 3$ configuration, and the degree of deviation.

3. Measures should be taken to prevent anthracite losses. Possibilities are:

(a) Lower backwash rates for longer times.

(b) Anthracite screens on the wash water gutters.

4. Backwash rates should be based on bed expansion.

5. The Cox device for measuring bed expansions should be employed to assist in establishing backwash rates.

6. The possibility of wasting elltered water immediately after backwashing should be investIgated. 
7. The proposed research should test the hypothesis that higher backwash rates produce better quality water.

\section{ACKNOWLEDGEMENTS}

The author is indebted to personnel of the Irradiation Processing Department, Hanford Atomic Products Operation, General Electric Company, who were of assistance during this study, particularly J. W. Frymier, R. W. PItman, L. D. Gustafson, and R. G. Geier. 


\section{BIBLIOGRAPHY}

Babbitt, H. E. and J. J. Doland, Water Supply Engineering, 4th Edition, MeGraw-Hill Book Conpany, (New York: 1949).

Baylis, J. R., "Test Program for Filter Evaluation at Hanford - Discussion," Jour. Am. Water Works Assn., 52, 2, 2.14, (February, 1960).

Black, A. P., "Basic Mechanisms of Coagulation," Jour. Am. Water Works Assn., 52, 4, 498, (April, 1960).

Camp, T. R., "Experience with Anthracite - Sand Filters - Discussion," Jour. Am. Water Works Assn., 53, 12, 1479, (December, 1961).

Camp, T. R., Water and Its Impurities, Reinhold Publishing Corp., (New York: 1963).

Camp, T. R., "Theory of Water Filtration," Jour. Sanit. Eng. Div., ASCE, 90, SA4, 1, (August, 1964).

Conley, W. R., C. W. Botsford, and R. W. Pitman, "Hanford Use of Experimental Water Filter Plant," AEC Document $\mathrm{HW}-45008$, (Alugust, 1956).

Conley, W. R., "Theory of Water Filtration - Discussion," Jour. Sanit. Eng. Div., ASCE, 21, SA2, 72, (April, 1965).

Cox, C. R., Water Supply Control, Bulletin No. 22, Bureau of Environmental Sanitation, New York State Department of Health, (Albany: 1952).

Cushing, C. E., "Plankton-Water Chemistry Cycles in the Columbia River," AEC Document HW-80500.

Deb., A. K., "Theory of Water Filtration - Discussion," Jour. Sanit. Eng. Div., ASCE, 21, SA2, 84, (April, 1965).

Eliassen, R., "Theory of Water Filtration - Discussion," Jour. Sanit. Eng. Div., ASCE, 21, SA2, 92, (April, 1965).

Ftir, G. M., and J. C. Geyer, Water Supply and Waste-Water Disposal, John Wiley and Sons, (New York: 1954).

Frymier, J. W., "Preliminary Investigation of Water Coagulation Characteristics As Affects Reactor Effluent Radionuclides," AEC Docurnent RL-REA-922, (Secret), (April, 1965).

Grune, W. N., "Investigation of the Effects of High Energy Ionizing Radiation on Colloidal Systems and Suspensions," Preprint, American Chemical Society meeting, August 30, 1964, Chicago, Illinois.

Hudson, H.E., "Theory of Water Filtration - Discussion," Jour. Sanit. Eng. Div. ASCE, 21, SA2, 80, (April, 1965).

Ives, K. J., "Theory of Water Filtration - Discussion," Jour. Sanit. Eng. Div., ASCE, 21, SA2, 99, (February, 1965). 
Jansen, G., Jx., "Alum Production Studies," AEC Document HW-73747 Rev., (July, 1962).

Kaufman, W. J., J. B. Nesbitt, M. I. Goldman, and R. Eliassen, "The Removal of Radioactive Anions by Water Treatment," AEC Document NYO-1571, (September, 1951).

O'Melia, C. R. and D. K. Crapps, "Some Chemical Aspects of Rapid Sand Filtration," Jour. Am. Water Works Assn., 56, 10, 1326, (October, 1964).

O'Melia, C. R., "Theory of Water Filtration - Discussion," Jour. Sanit. Eng. Div., ASCE, 21, SA2, 92, (April, 1965).

Pitman, R. W., "Water Treatment - Theory and Practices - As Used at Hanford Atomic Products Operation," AEC Document HW-83801, (August 25, 1965).

Pitman, R. W., "Increasing Water Filtration at Hanford," AEC Document RL-REA-l, (August, 1964).

Friesing, C. P., "A Theory of Coagulation Useful for Design," Ind. and Eng. Chem., 54, 8, 43, (August, 1962).

"Process Standards - Reactor Cooling Water," AEC Document HW-27155, (Secret). Riddick, T. M., "Zeta Potential: New Tool for Water Treatment," Chem. Eng., June $26,1961$.

Sedlander, N. R. and C. D. Getes, "Effect of Alkyl Benzene Sulfonate on Hydrous Alum Floc," Ind. and Eng. Chem., Process Design and Dev. Quarterly, 4, 1 , 55, (January, 1965).

Silker, W. B., "Reducing Radioisotope Concentrations in Reactor Effluent by High Congulant Feed," Jour. Am. Water Works Assn., 55, 3, 355, (March, 1963).

Standard Methods for the Examination of Water, Sewage and Industrial Wastes, American Public Health Association, Inc. (New York: 1955).

Stanley, D. R., "Theory of Water Filtration - Discussion," Jour. Sanit. Eng. Div., ASCE, 21, SA2, 71, (April, 1965).

Touhill, C. J. and H. M. Clark, "Radionuclide Adsorption by Manganese Dioxide," Rensselaer Polytechnic Institute, Troy, New York, (1964).

Water Treatment Plant Design, An erical Society of Civil Engineers, Manual of Engineering Practice No. 19, (1940). 

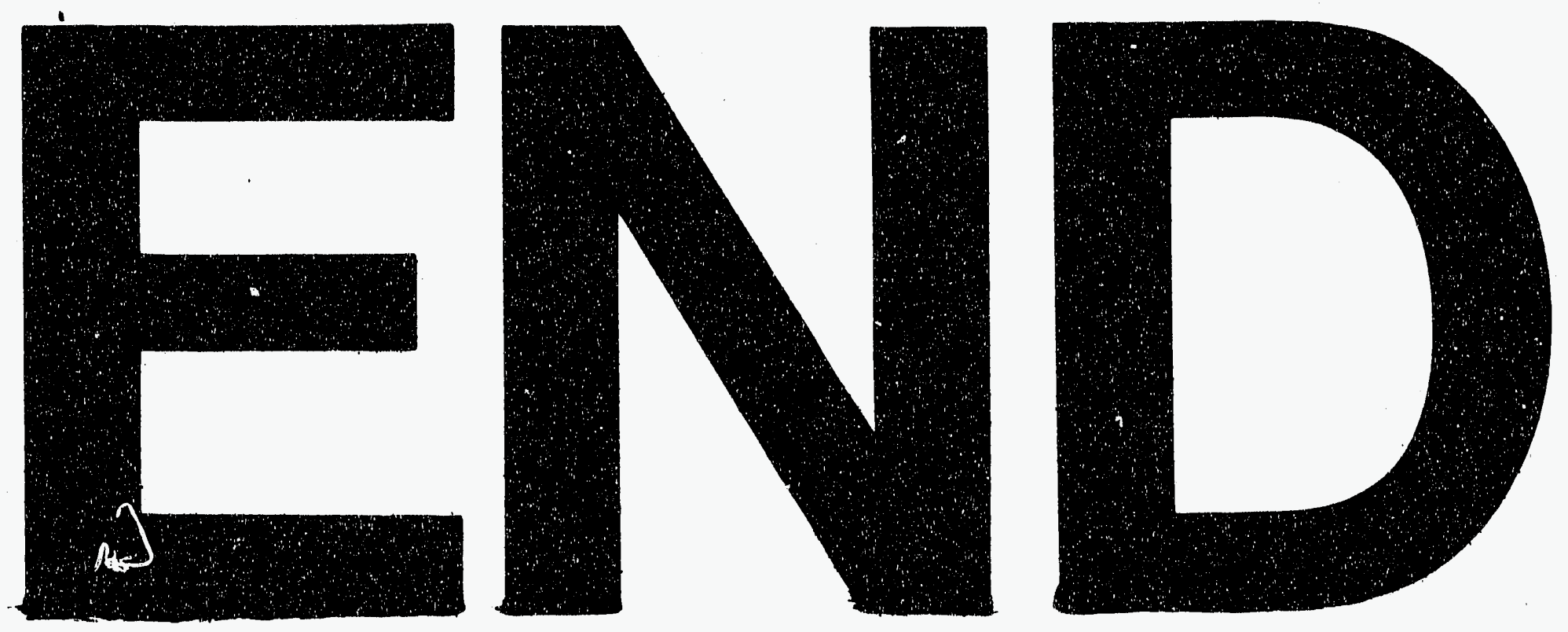

.
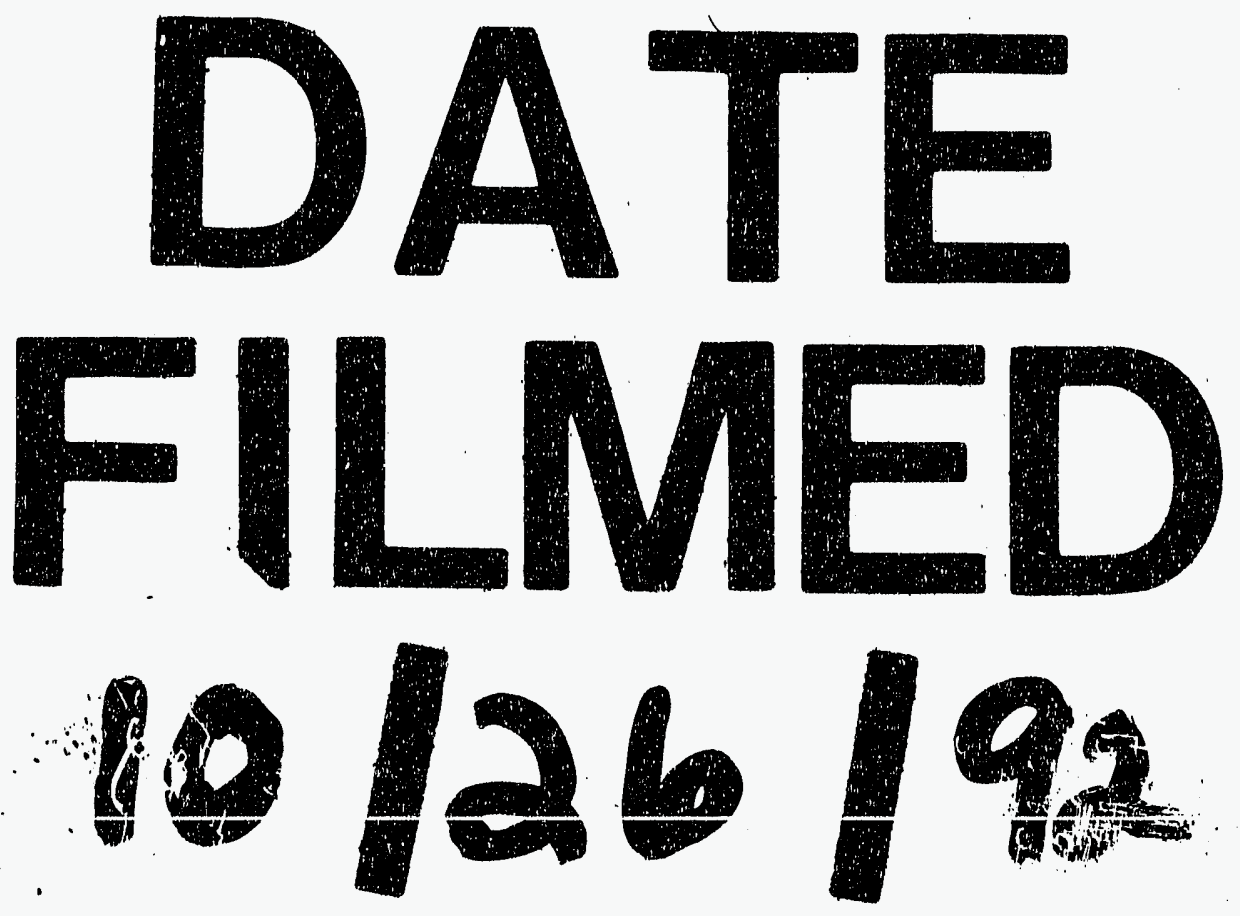
